\title{
A Lightning Protection for Space Vehicles
}
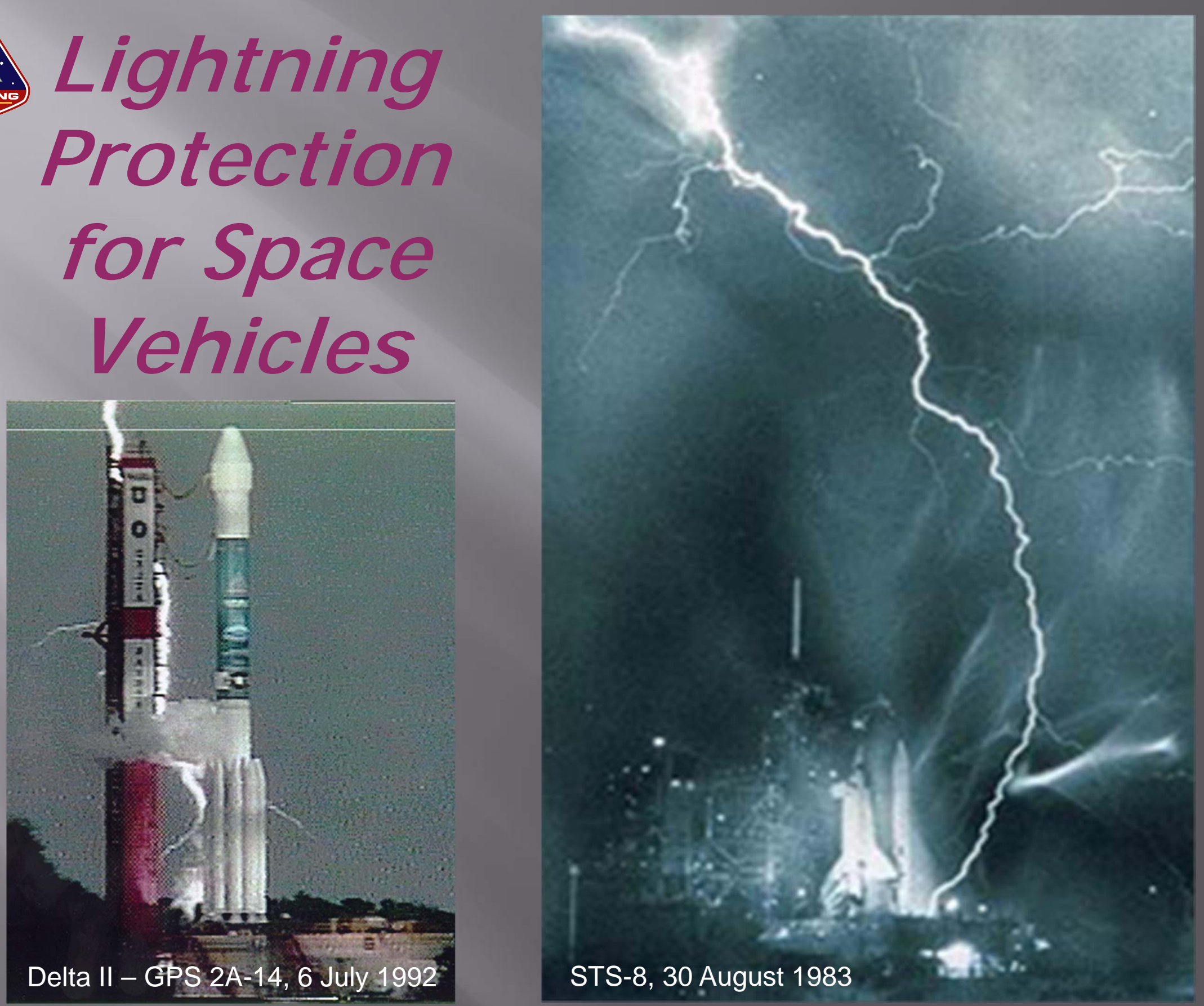


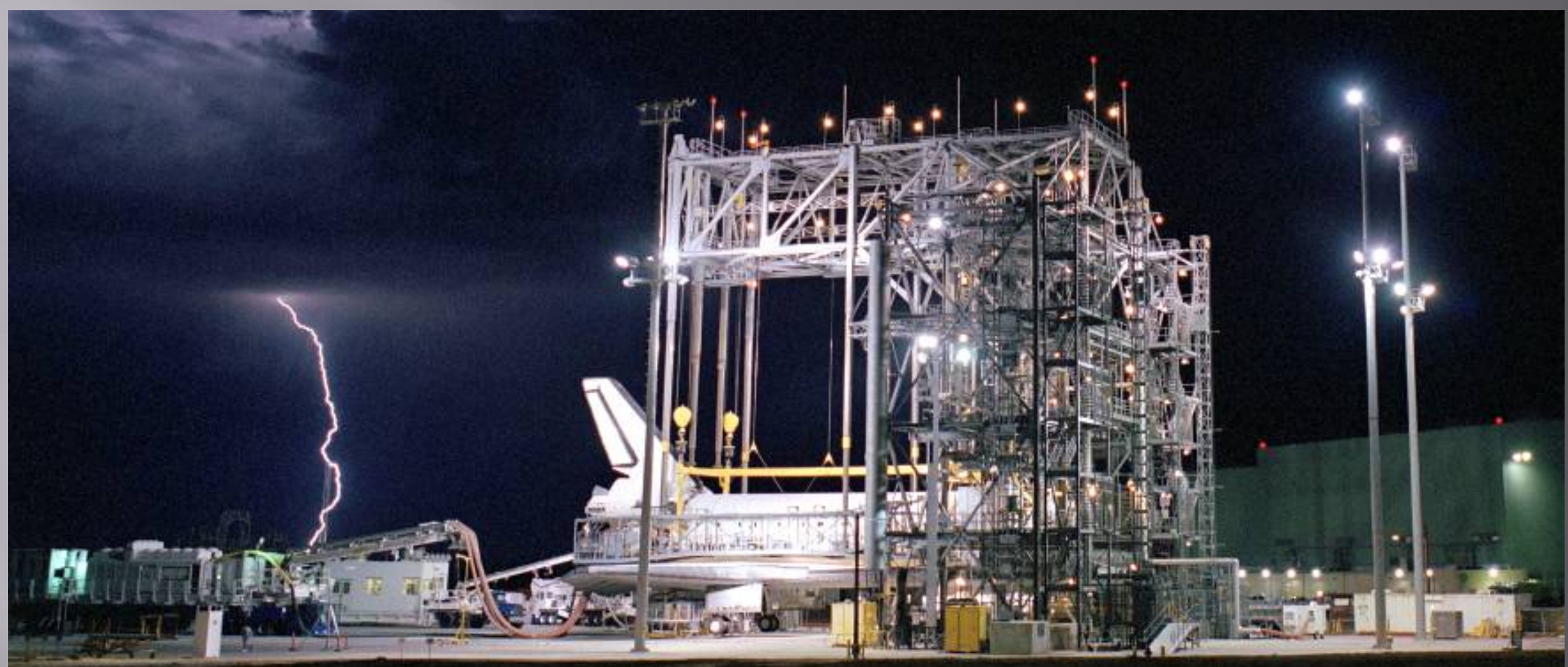

Nasa

NASA Dryden Flight Research Center Photo Collection http://www.dfrc.nasa.gov/Gallery/Photo/index.html

NASA Photo: EC05-0166-22 Date: August 14, 2005 Photo By: Tom Tschida

Lightning strikes in the distance as the Space Shuttle Discovery receives post-flight processing in the Mate-Demate Device, following its landing at NASA DFRC. 


\section{Topics for Discussion}

- Introduction

- Historical Events

- Threat Definition

- Climatology at KSC

- First Line of Protection

- Weather Prediction, Catenary Systems, and Detection Systems

- Operational Impacts

- Ground Operations

- Flight Operations
- Requirements

口 Documents

- Historical (AE4L, 1757, 1795)

- Shuttle 07636 \& 20007

- Current SAE 54XX series

- Direct \& Indirect Effects Considerations

- Protection Design

- Zoning

- Lightning Environment Definition

- Identify Critical Hardware \& Establish Protection Criteria

- Summary and Closing Remarks 


\section{Introduction}

- Lightning is a capricious and potentially deadly hazard that is common to all spacecraft. For expendables, the threat is restricted to pre-launch ground processing and ascent phases. For others, such as the Shuttle and Constellation Programs, all phase of operations, except for on-orbit, expose the vehicle to some level of threat. This presentation will introduce the participants to some historical lightning events, climatology at Kennedy Space Center, a discussion of weather prediction and physical protection systems, operational impacts and design considerations for hardware.

- What I hope you take away with you today is a sense of what kind of threat and design impact lightning presents to us as spacecraft developers and engineers. I have tried to strike (pun intended!) a balance between too much and not enough detail. I will be interested in hearing your feedback on how well I accomplished that.

- What I won't be able to do today is make all of you experts in lightning. The topic is very broad, and can be quite complex, and we simply don't have the time to work through all of that. I have been working in aerospace for $25+$ years, about half of that in the commercial and military helicopter industry. Helicopters are very juicy targets for lightning events, and designing protection schemes for them is challenging, to say the least. Even with that background, I certainly don't claim to know "everything" about lightning. In fact, the longer I work with the topic, the more I realize I don’t know. 


\section{Environment Historical Events}

- Apollo 12

- Nov 1969

- Struck twice: 36 sec \& 52 sec after launch

- Manual fuel cell reset to recover

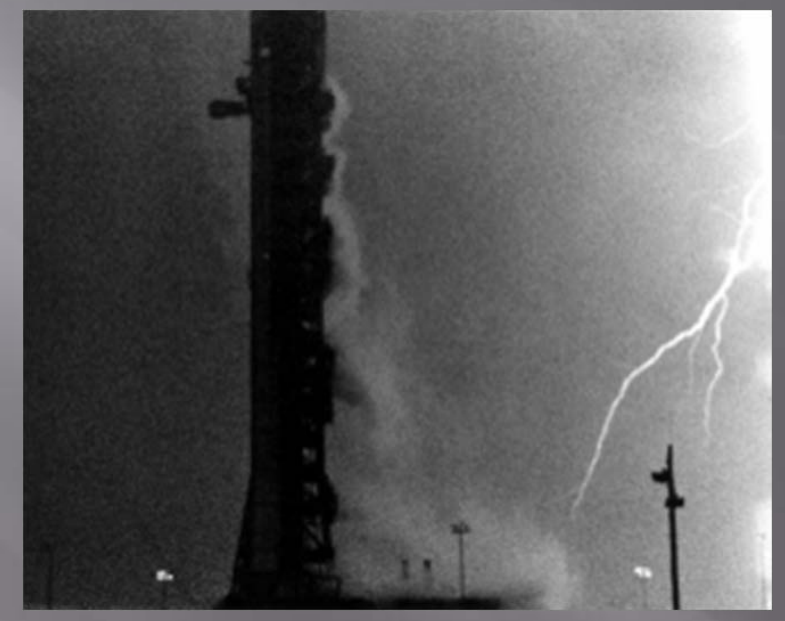

- Atlas Centaur Flight 67 - Mar 1987

- Struck 4 times (multistroke event), 48 sec after launch

- Transient changed a single memory location in a DCU and caused a hard-over command in the engine yaw channel

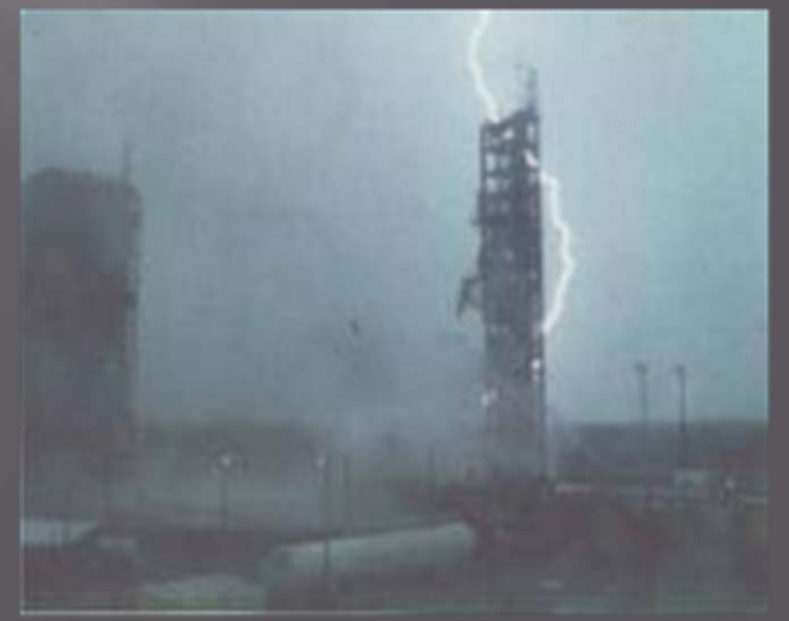




\section{Environment Historical Events}

- STS-115

- Aug 2006

- 50kA strike to Pad 39B lightning mast

- 3 days \& hundreds of engineers \& managers for determination of safety of flight

\section{5}




\section{Threat Definition}

- Flashes, Leaders, Streamers, \& Return Strokes

- Lightning is a high voltage, high current natural phenomenon associated with the transfer of electric charge

- Thunderstorms, sandstorms, snowstorms, and volcanic activity

口 Cloud to cloud

- Cloud to ground

口 $\quad$ Evidence these are more severe than intracloud events

- Anatomy of a cloud to ground flash

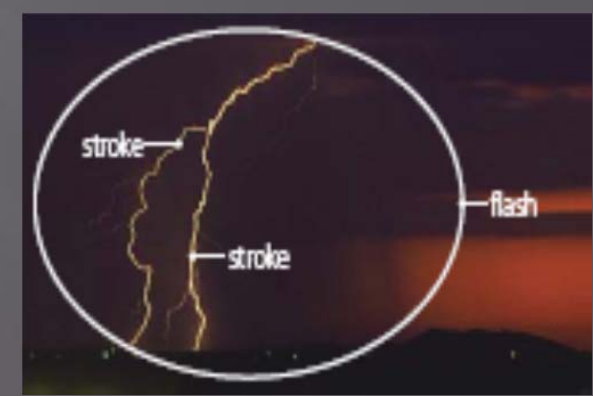

- Once sufficient electrical charge has built up in a cloud, a column of charged particles forms and begins to propagate in a direction normal to local electric field lines

- This leader will continue to work its way downward until a strong oppositely charged region on the ground develops an upward moving streamer

- When the two meet, charge transfer occurs

- This charge transfer is called a return stroke

- The point at which the streamer and leader make contact is called the striking distance

- Multiple subsequent leader/streamer/return stroke events may follow

- All of the above constitute a single flash event 


\section{Lightning Threat}

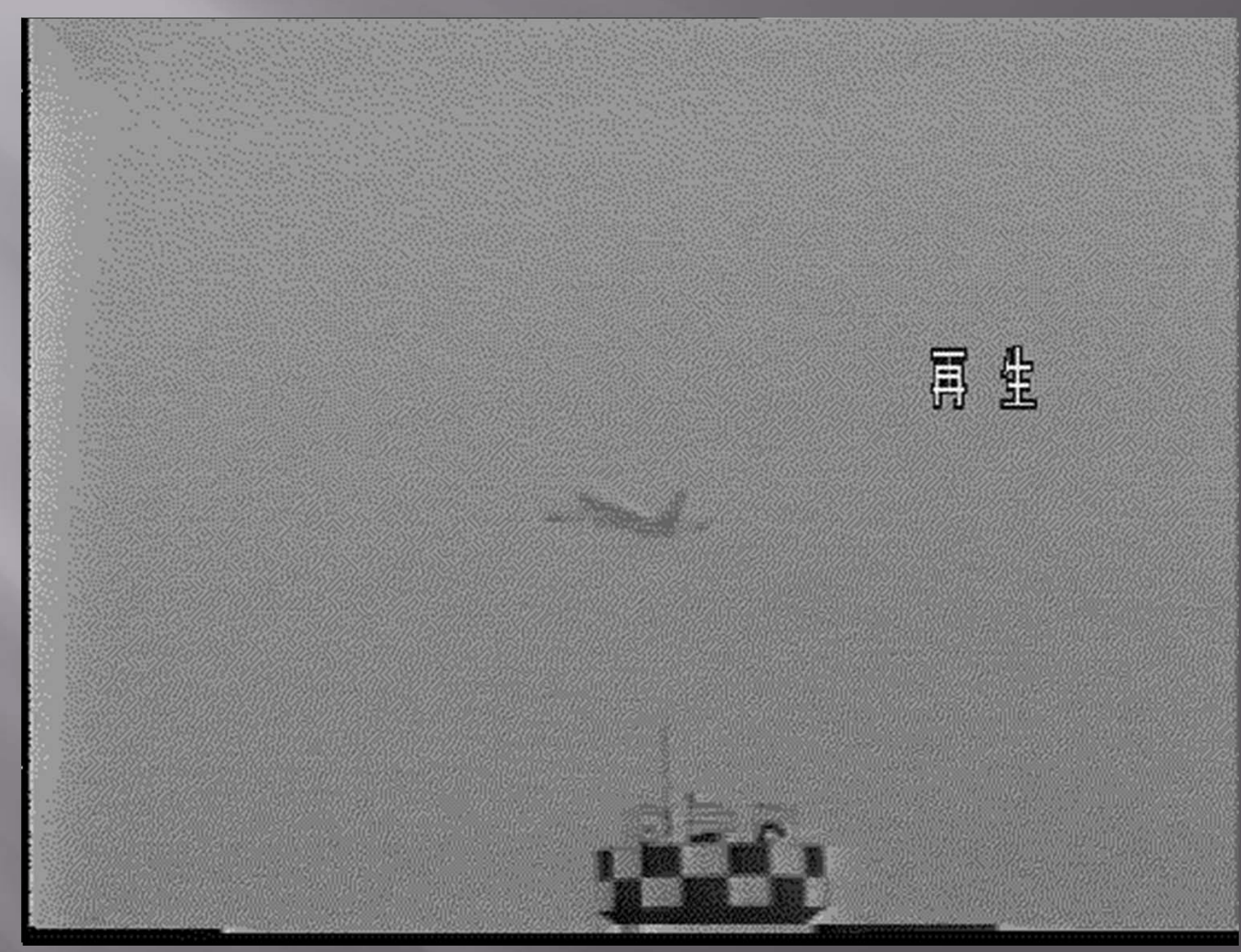




\section{hthing Climatology at KSC}

- Lightning climatology at KSC has been thoroughly researched and documented by many folks over many years.

- Such studies have shown that lightning behavior over many years at KSC tends to follow a pattern of behavior.

\begin{tabular}{|c|c|c|c|c|c|c|c|c|c|c|c|c|c|c|}
\hline $\begin{array}{c}\text { Time Block } \\
\text { (UTC) }\end{array}$ & $\begin{array}{c}\text { Time Block } \\
\text { (EST) }\end{array}$ & $\begin{array}{c}\text { Time Block } \\
\text { (EDT) }\end{array}$ & Jan & Feb & Mar & Apr & May & Jun & Jul & Aug & Sep & Oct & Nov & Dec \\
\hline 00 to 06 & 20 to 02 & 19 to 01 & 6 & 93 & 64 & 124 & 206 & 643 & 310 & 355 & 1509 & 505 & 2 & 5 \\
\hline 01 to 07 & 21 to 03 & 20 to 02 & 22 & 113 & 50 & 128 & 179 & 461 & 211 & 122 & 1250 & 521 & 2 & 5 \\
\hline 02 to 08 & 22 to 04 & 21 to 03 & 22 & 112 & 35 & 206 & 134 & 237 & 105 & 247 & 902 & 489 & 2 & 3 \\
\hline 03 to 09 & 23 to 05 & 22 to 04 & 22 & 93 & 47 & 197 & 105 & 42 & 90 & 226 & 680 & 105 & 2 & 3 \\
\hline 04 to 10 & 00 to 06 & 23 to 05 & 26 & 53 & 49 & 165 & 35 & 16 & 83 & 213 & 423 & 124 & 2 & 3 \\
\hline 05 to 11 & 01 to 07 & 00 to 06 & 27 & 39 & 43 & 102 & 29 & 17 & 73 & 210 & 111 & 123 & 2 & 3 \\
\hline 06 to 12 & 02 to 08 & 01 to 07 & 26 & 41 & 38 & 100 & 10 & 80 & 75 & 195 & 110 & 97 & 1 & 3 \\
\hline 07 to 13 & 03 to 09 & 02 to 08 & 12 & 22 & 40 & 89 & 3 & 83 & 71 & 200 & 85 & 76 & 0 & 3 \\
\hline 08 to 14 & 04 to 10 & 03 to 09 & 12 & 14 & 26 & 8 & 5 & 86 & 72 & 44 & 76 & 76 & 0 & 2 \\
\hline 09 to 15 & 05 to 11 & 04 to 10 & 20 & 14 & 14 & 8 & 4 & 90 & 57 & 31 & 71 & 32 & 9 & 1 \\
\hline 10 to 16 & 06 to 12 & 05 to 11 & 18 & 16 & 9 & 19 & 5 & 175 & 19 & 38 & 52 & 2 & 9 & 3 \\
\hline 11 to 17 & 07 to 13 & 06 to 12 & 12 & 16 & 10 & 46 & 9 & 304 & 83 & 188 & 204 & 1 & 9 & 2 \\
\hline 12 to 18 & 08 to 14 & 07 to 13 & 12 & 30 & 16 & 46 & 34 & 589 & 296 & 1166 & 394 & 4 & 11 & 2 \\
\hline 13 to 19 & 09 to 15 & 08 to 14 & 10 & 45 & 66 & 47 & 76 & 1148 & 1272 & 1986 & 603 & 9 & 12 & 4 \\
\hline 14 to 20 & 10 to 16 & 09 to 15 & 11 & 51 & 123 & 48 & 114 & 2180 & 2515 & 2859 & 735 & 17 & 13 & 31 \\
\hline 15 to 21 & 11 to 17 & 10 to 16 & 8 & 56 & 171 & 66 & 391 & 2954 & 3396 & 4093 & 873 & 22 & 5 & 50 \\
\hline 16 to 22 & 12 to 18 & 11 to 17 & 6 & 71 & 187 & 58 & 655 & 3663 & 4244 & 4527 & 1024 & 77 & 5 & 56 \\
\hline 17 to 23 & 13 to 19 & 12 to 18 & 6 & 114 & 208 & 150 & 751 & 4004 & 4680 & 4690 & 1060 & 200 & 6 & 56 \\
\hline 18 to 00 & 14 to 20 & 13 to 19 & 27 & 103 & 270 & 650 & 764 & 4156 & 4568 & 4079 & 887 & 220 & 5 & 56 \\
\hline 19 to 01 & 15 to 21 & 14 to 20 & 27 & 87 & 232 & 656 & 756 & 3776 & 3695 & 3487 & 962 & 220 & 5 & 54 \\
\hline 20 to 02 & 16 to 22 & 15 to 21 & 26 & 90 & 204 & 658 & 761 & 2965 & 2557 & 2645 & 1187 & 244 & 4 & 30 \\
\hline 21 to 03 & 17 to 23 & 16 to 22 & 21 & 104 & 156 & 649 & 514 & 2382 & 1706 & 1445 & 1276 & 667 & 3 & 12 \\
\hline 22 to 04 & 18 to 00 & 17 to 23 & 21 & 127 & 143 & 678 & 319 & 1614 & 903 & 1017 & 1401 & 623 & 3 & 4 \\
\hline 23 to 05 & 19 to 01 & 18 to 00 & 26 & 98 & 127 & 622 & 225 & 1143 & 413 & 707 & 1525 & 502 & 2 & 5 \\
\hline
\end{tabular}




\section{Tumber of Flash Events}

Recorded Number of Lightning Strikes w/in 5 nmi of KSC Midway Between VAB and Pad 39 Complex as a Function of Time of Year \& Day (Source: 1997-2007 NLDN 6 Hour Data Blocks)

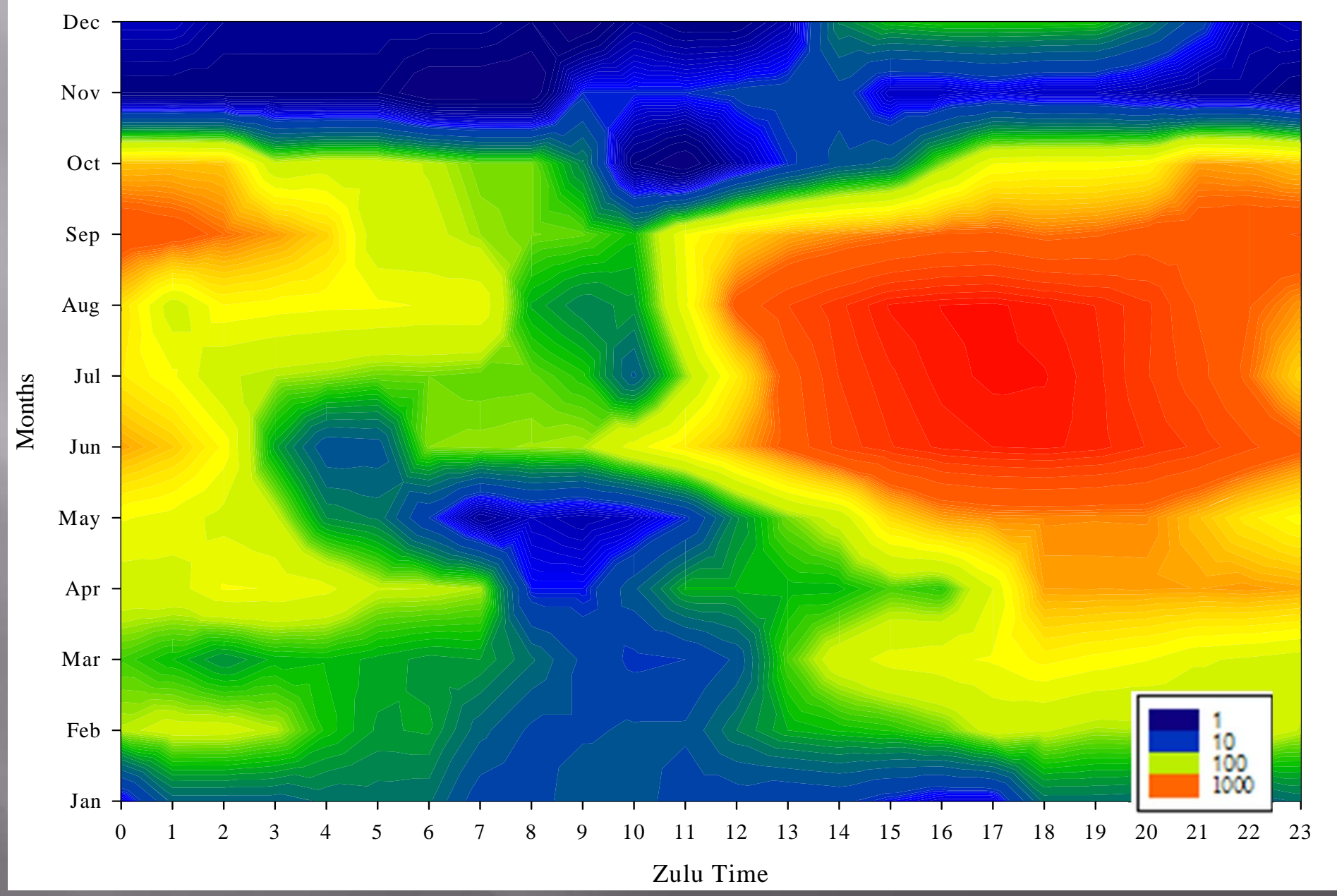


- In spite of the foregoing, it is very important to realize that lightning may occur at any time of day, at any time of year, and serious consequences may arise from a single event.

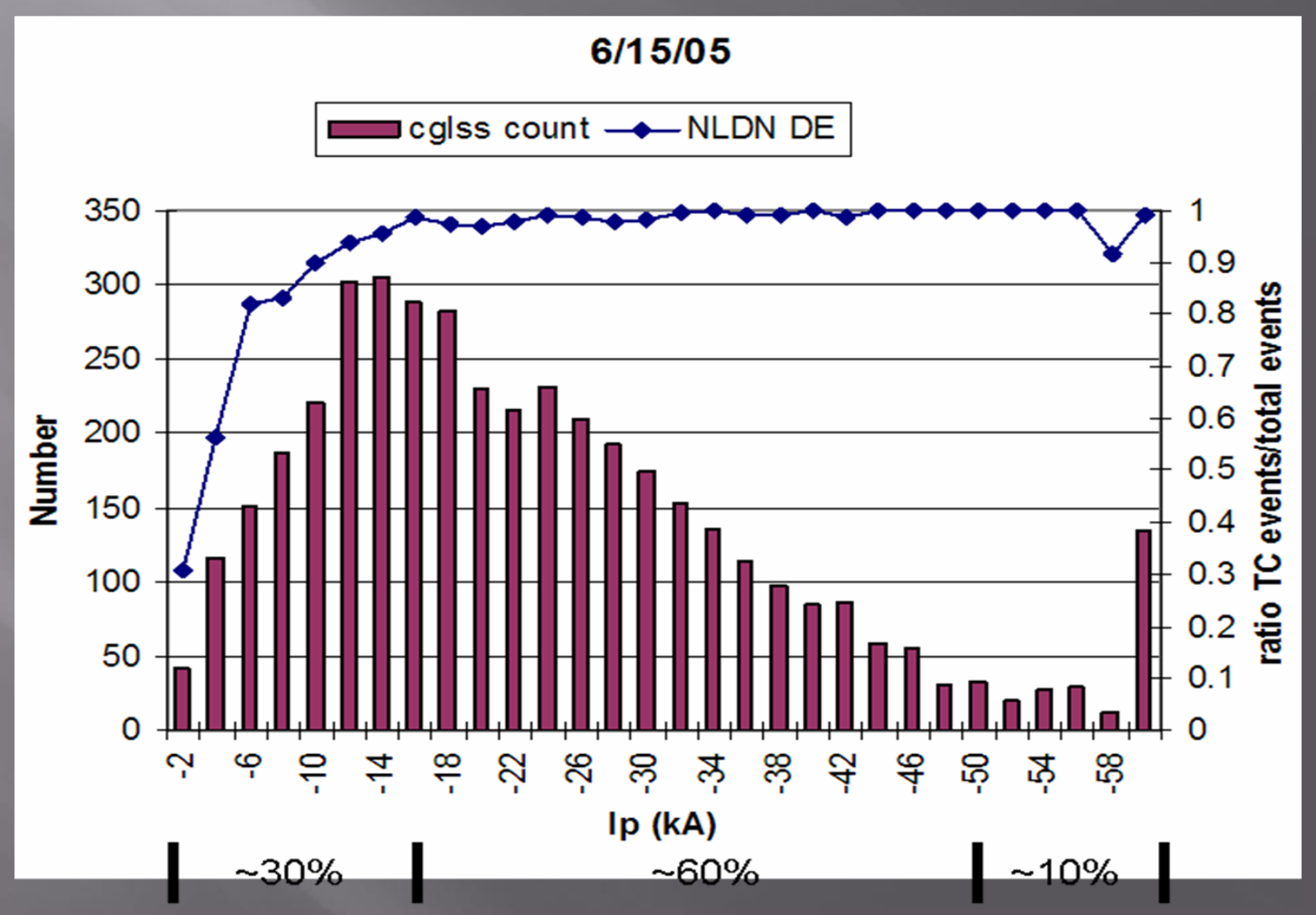




\section{Magnetic Field as a Function of Distance}

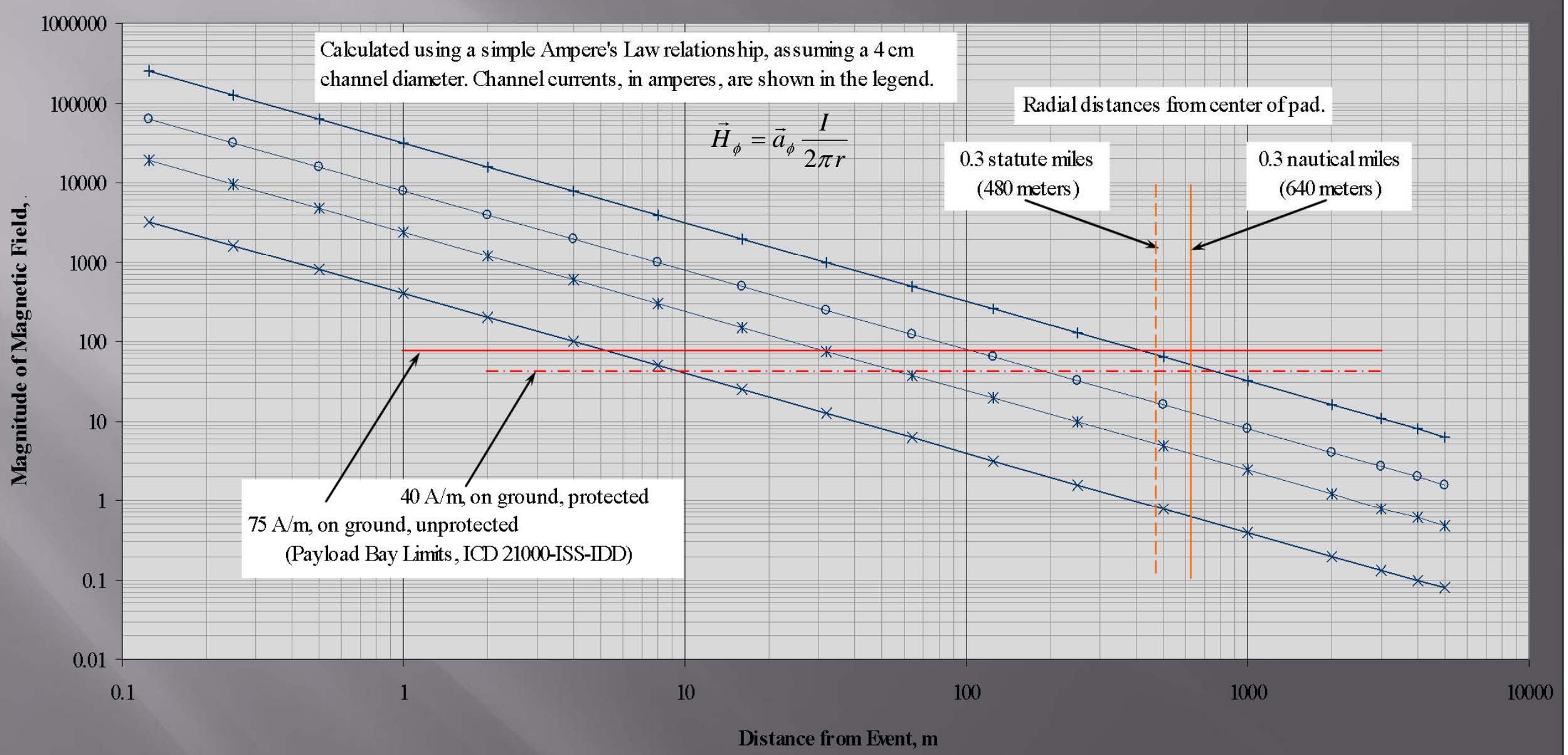




\section{Magnetic Field as a Function of Distance}

- To be a bit more specific, the following derivation supports the use of the preceding approximation.

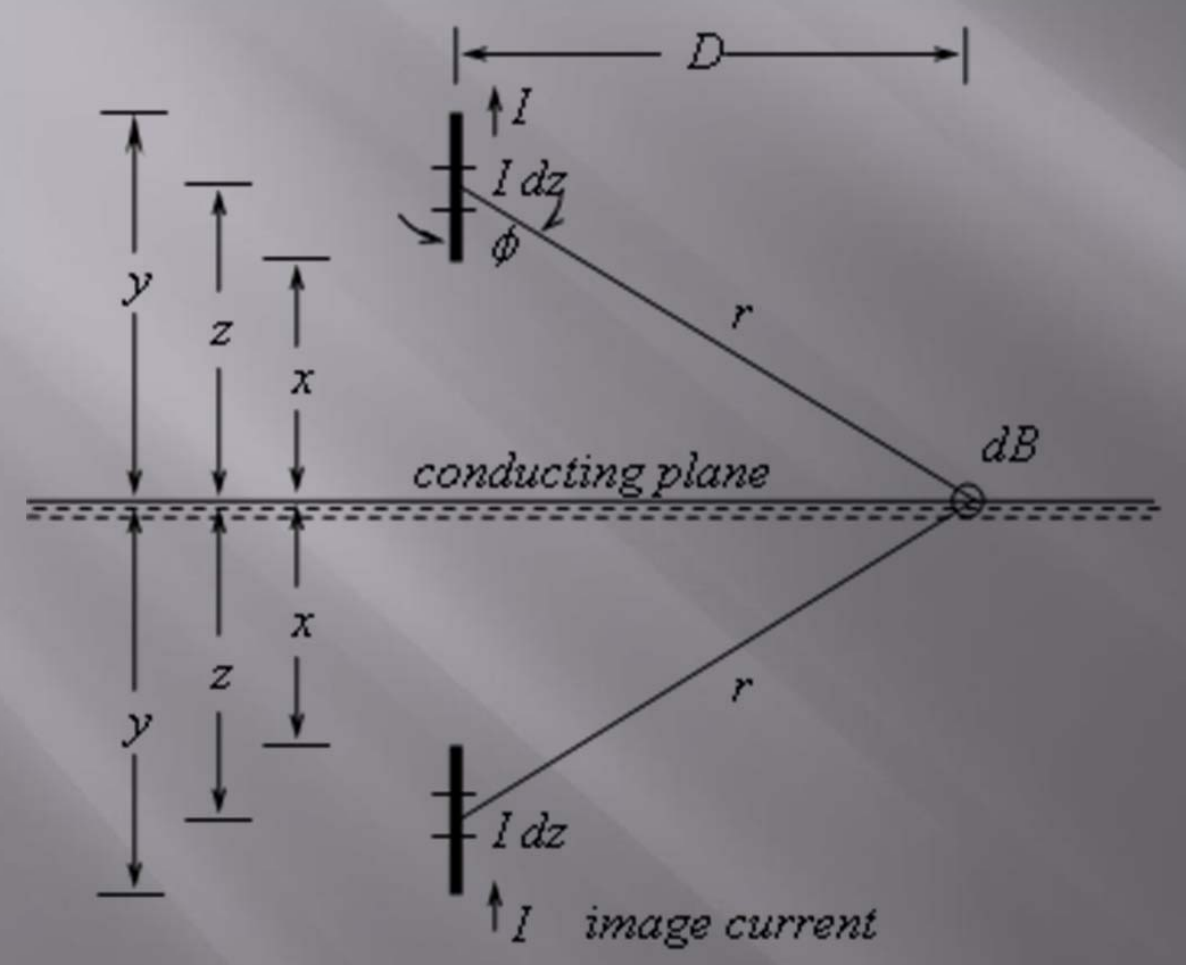

$$
\begin{aligned}
& d \vec{B}=\frac{\mu_{0} I d z}{4 \pi r^{2}}\left(\vec{a}_{I} \times \vec{a}_{r}\right) \\
& d B=\frac{\mu_{0} I d z}{4 \pi r^{2}} \sin \phi=\frac{\mu_{0} I d z}{4 \pi r^{2}} \frac{D}{\left(z^{2}+D^{2}\right)^{3 / 2}} \\
& \int_{z=x}^{z=y} d B=\frac{\mu_{0} I}{2 \pi D}\left[\frac{y}{\left(y^{2}+D^{2}\right)^{1 / 2}}-\frac{x}{\left(x^{2}+D^{2}\right)^{1 / 2}}\right] \\
& B=\frac{\mu_{0} I}{2 \pi D} \frac{H}{\left(H^{2}+D^{2}\right)^{1 / 2}}, \text { for } y=H, x=0 \\
& B \cong \frac{\mu_{0} I}{2 \pi D}[H>D] \\
& B \cong \frac{\mu_{0} I}{2 \pi D^{2}} \quad[H<<D]
\end{aligned}
$$


- Weather Prediction

\section{First Line of Protection}

- In general, for space vehicles the best means of lightning protection turns out to be avoidance. Weather prediction plays a major role in providing that protection, and is a prime factor in decisions for launch, re-entry, and hardware relocation on the ground.

- Shielding and Catenary Systems

- At the next level, space vehicles are increasingly dependent on methods of shielding. The External Tank used for Shuttle operations is moved from the Michoud facility in Louisiana to Kennedy Space Center in a barge that is protected by a perforated steel covering.
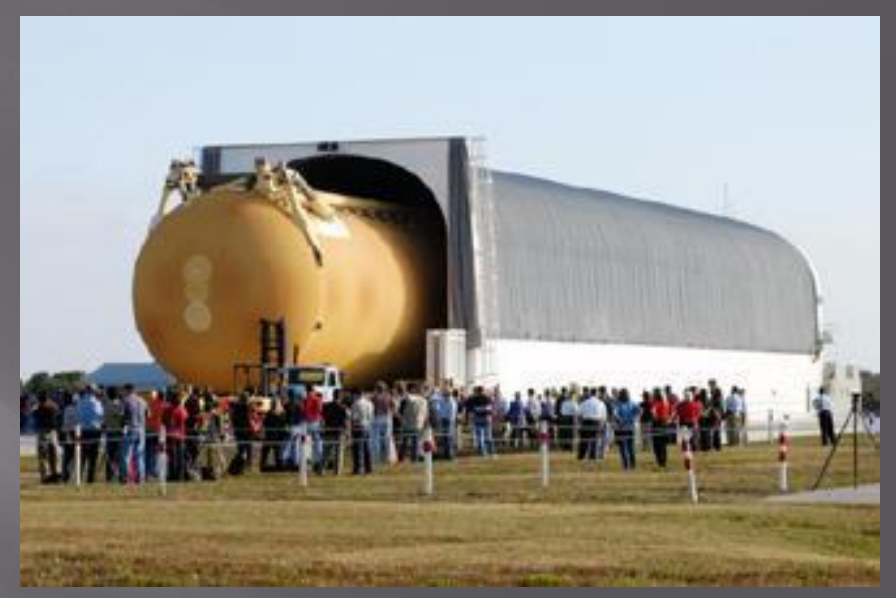

- On the launch pad, catenary wire systems are commonly employed that provide excellent protection from a direct attachment. Shuttle has used a single wire configuration for the entire life of the Program, and while the catenary itself and its support mast have been struck many times, there has never been a direct attachment to the vehicle on the pad. 


\section{Weather Prediction}

- All forecasts used for official purposes at KSC come from one of two outside sources.

- The 45th Weather Squadron, located at Patrick AFB, Fl, provides weather observations, forecasts, advisories and warnings, and staff support to the 45th Space Wing, NASA, and tenant units.

- It also provides weather services for all DoD and civilian space and ballistic missile launch operations on the Eastern Range, Cape Canaveral Air Station, Space Shuttle Operations at Kennedy Space Center and overseas abort landing sites, cross-country Space Shuttle orbiter ferry flights, and Patrick AFB flight operations 24 hours-per-day.

- The Space Flight Meteorology Group (SMG), a National Weather Service branch based at Johnson Space Center (JSC), handles all Shuttle and on-orbit and landing forecasts, including KSC and the Trans-Atlantic Abort Landing sites .

- Kennedy Space Center's Weather Office coordinates the efforts of the many different meteorological entities that support the space program and ensures that NASA's needs are met. The office also plays a major role in setting weather criteria for launch and landing, and provides crucial expertise for the planning of new vehicle operations. 


\section{Catenary Systems}

- The wires in a catenary system are intended to intercept the lightning, and downconductors convey the current away from the catenary system to the ground. The catenary system prevents direct lightning currents from reaching the vehicle. This type of system is effective, but requires a fair amount of construction effort and space, with tall poles, a wire net, down-conductors, and a good ground system.

- The catenary system at KSC located at pads 39A and 39B comprises an 80 -foot fiberglass mast on top of the Fixed Service Structure, a 1-inch stainless steel cable that runs over the top of the mast, and a 4-foot-high lightning rod on top of the mast connected to the cable. The cable stretches 1,000 feet in two directions to where each end is anchored and grounded. Its appearance is similar to that of a suspension bridge tower and its supporting cables.

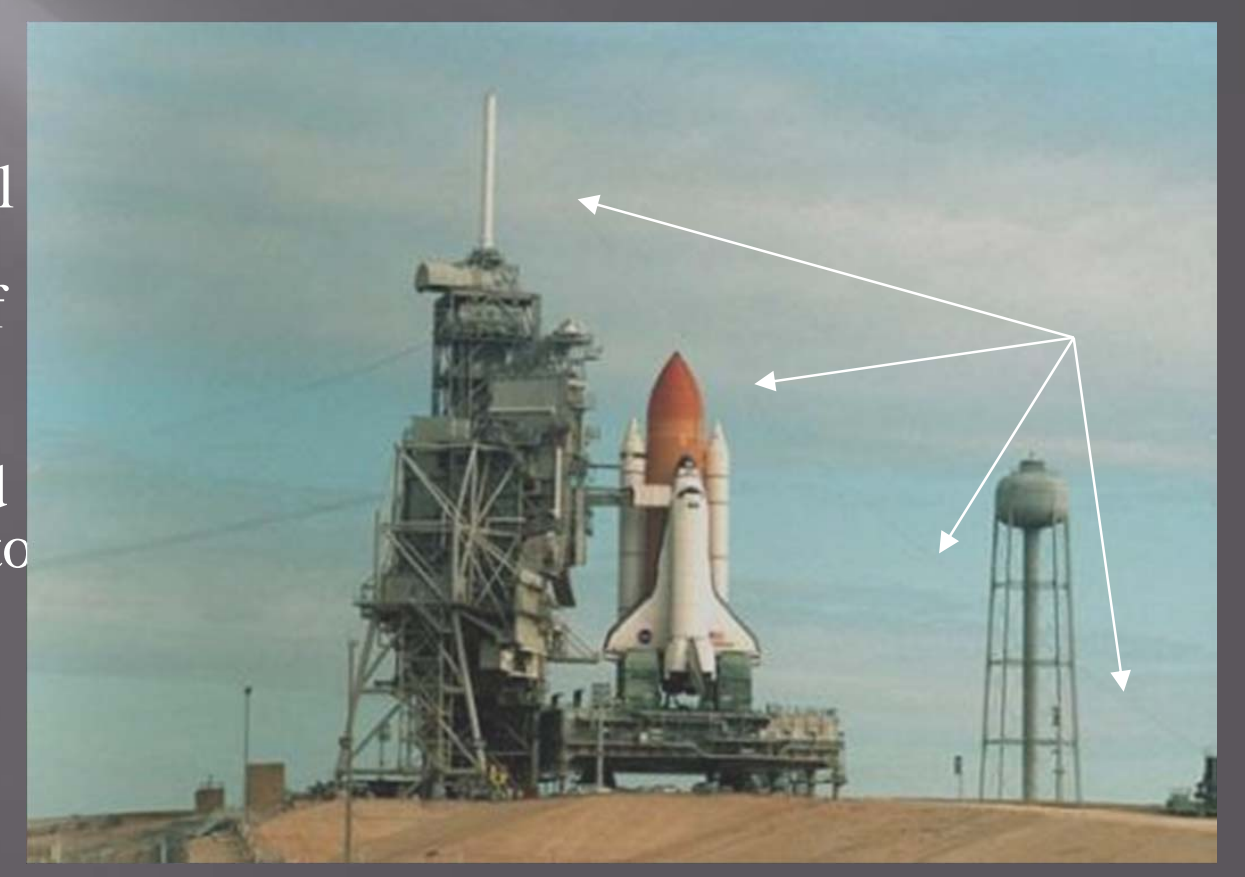




\section{Catenary Systems}

- Constellation Program will be replacing the older, single wire system with a new, three tower system, depicted here in an artist's sketch. This system does in fact create a net over the pad, and is constructed such that the vehicle will fly through a pentagram-shaped opening in the net. The new system features large cables strung between three 594-foot-tall steel and fiberglass towers.

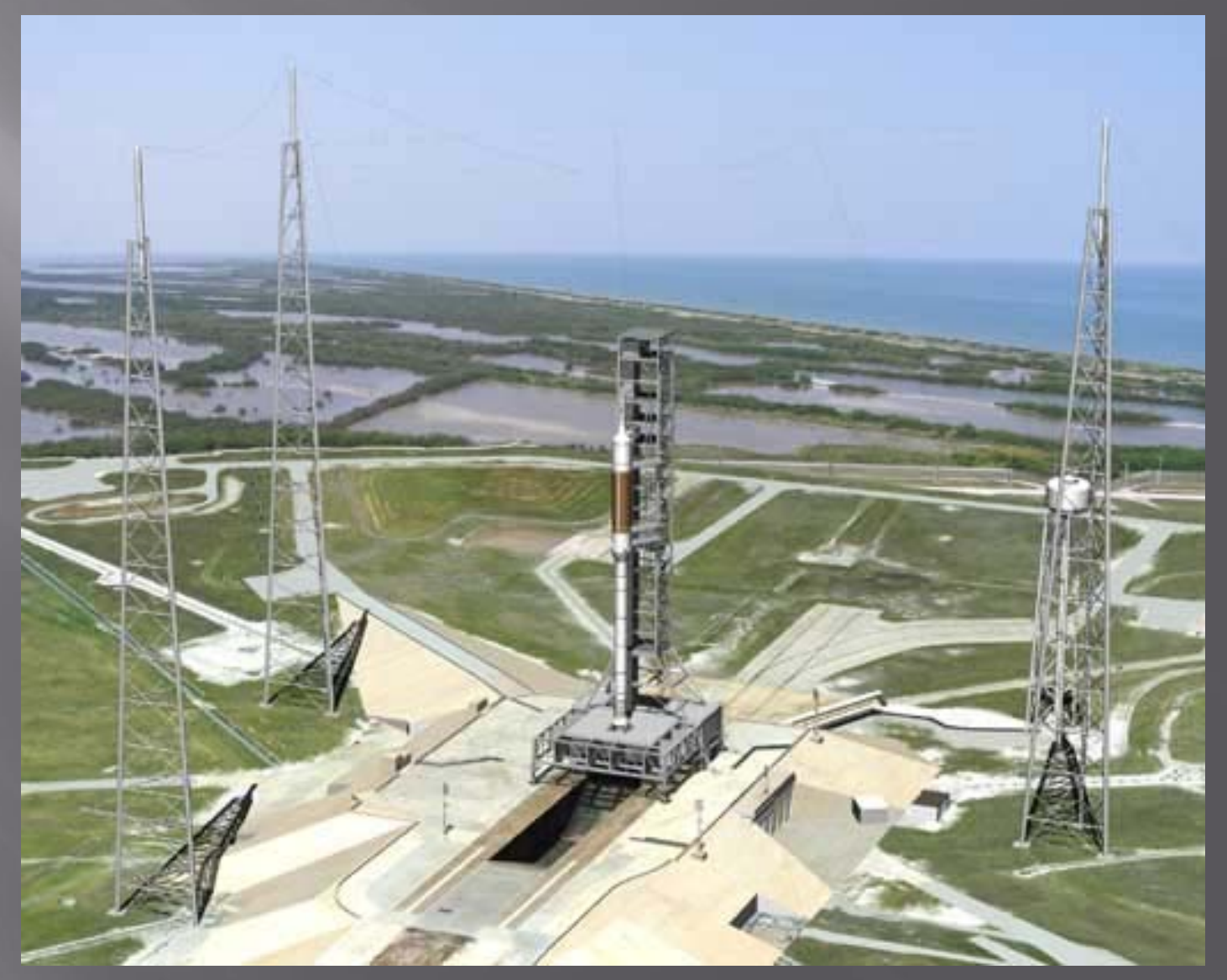


- Here's a better look at the design. Construction is expected to complete in 2010. Note the pentagram-shaped opening circled in orange.

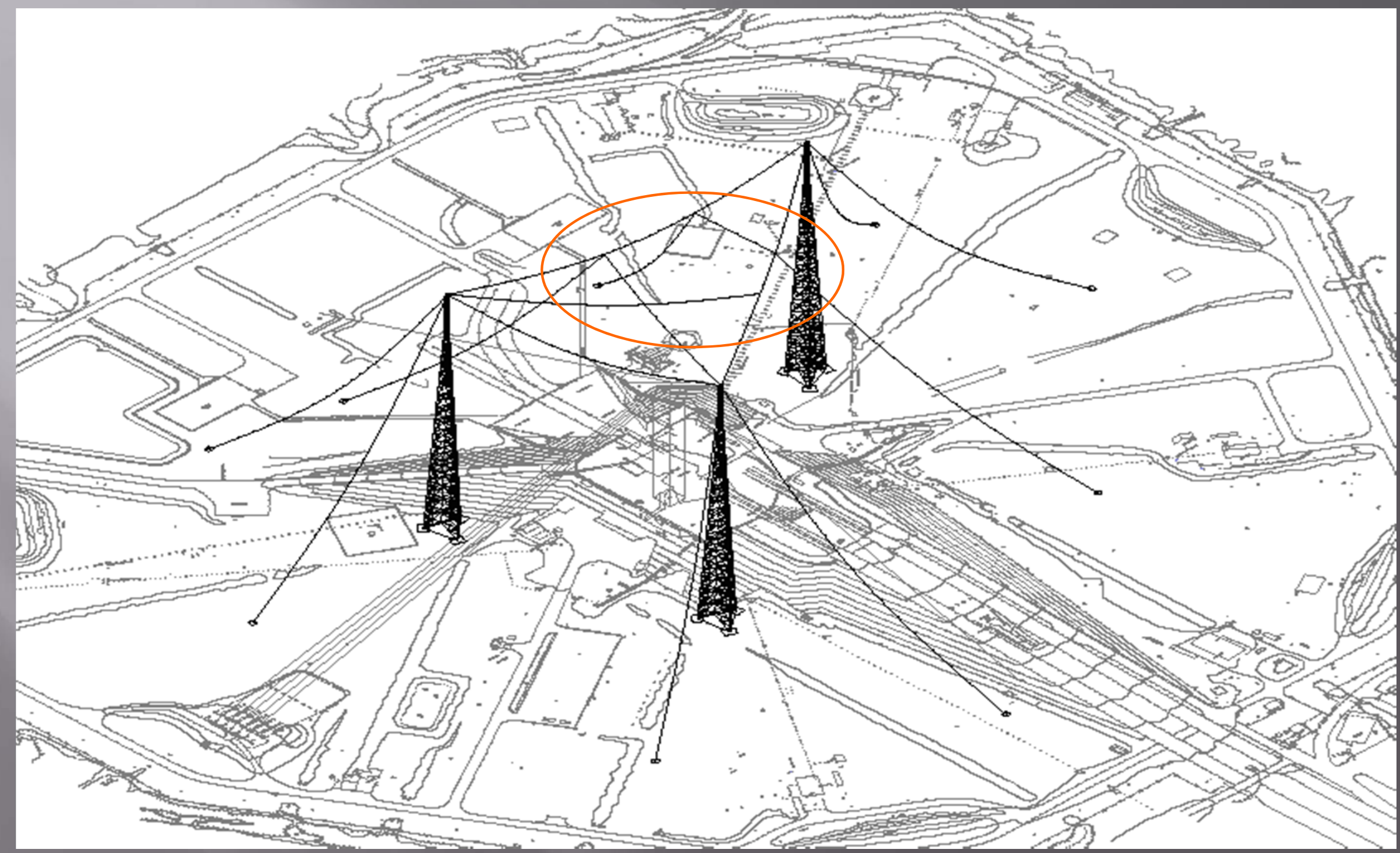




\section{Detection Networks}

- Launch Pad Lightning Warning System (Field Mill Network): Thirty-one advanced field mill sites around KSC and Cape Canaveral Air Force Station provide data on lightning activity and surface electric fields induced by charge aloft. This data helps forecasters determine when electric charge aloft may be sufficient to create triggered lightning during launch, and to determine when to issue and cancel lightning advisories and warnings.

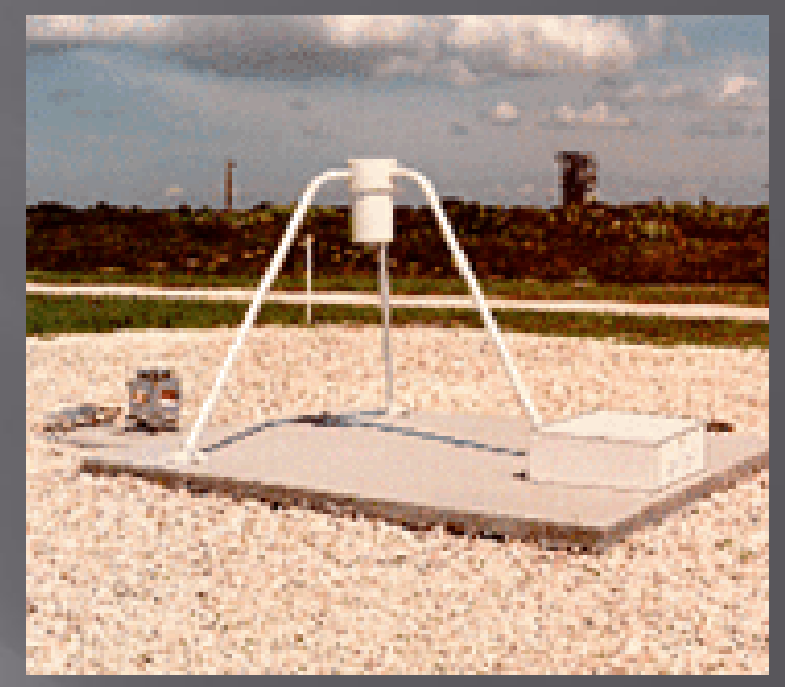

- National Lightning Detection Network: Plots cloud to ground lightning nationwide. Used to help ensure safe transit of the Space Shuttle orbiter atop the Shuttle Carrier Aircraft between Edwards Air Force Base in California and the Kennedy Space Center in Florida. It is also used to assess lightning beyond the 125-mile range of the Lightning Detection System. 


\section{Detection Networks}

- Lightning Detection And Ranging (LDAR): Developed by NASA at the Kennedy Space Center, LDAR plots intracloud, cloud to cloud and cloud to ground lightning in three dimensions within 75 nautical miles of the Kennedy Space Center. Location accuracy is very high within 25 nautical miles. LDAR data is important in determining the beginning and end of lightning conditions.

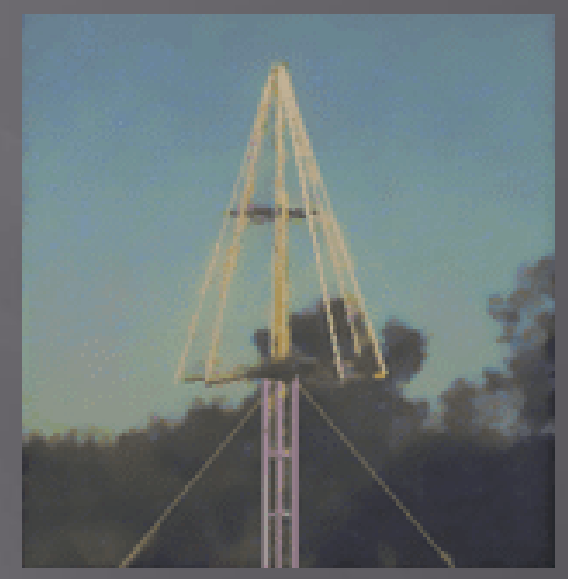

- Cloud to Ground Lightning Surveillance System (CGLSS): Detects and plots cloud to ground lightning strikes within 125 nautical miles of the Kennedy Space Center. Location accuracy is optimum within 30 nautical miles. Locations of strikes are color coded according to time of occurrence. 


\section{Detection Networks}

CGLSS and an upgraded version of LDAR, LDAR II, have recently been combined into a system called the 4 Dimensional Lightning Surveillance System (4DLSS). LDAR II is very capable of detecting lightning activity above $1000 \mathrm{ft}$. CGLSS directly complements LDAR II, and the necessary software has been written and is now operational at KSC. Detection accuracy of 4DLSS has been verified to be very close to $100 \%$.

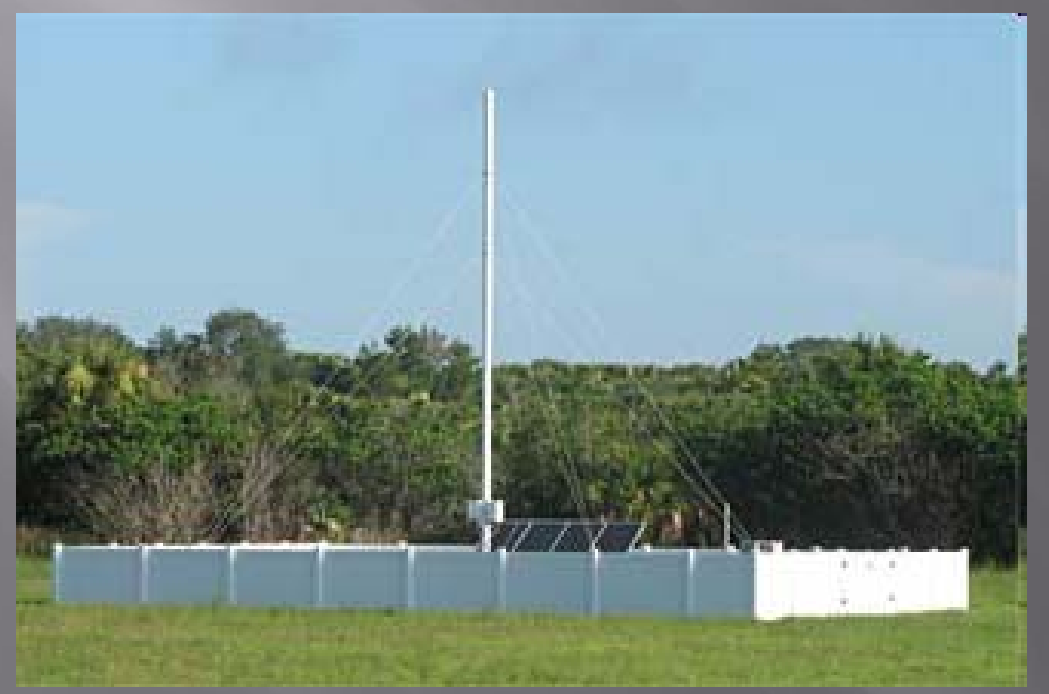

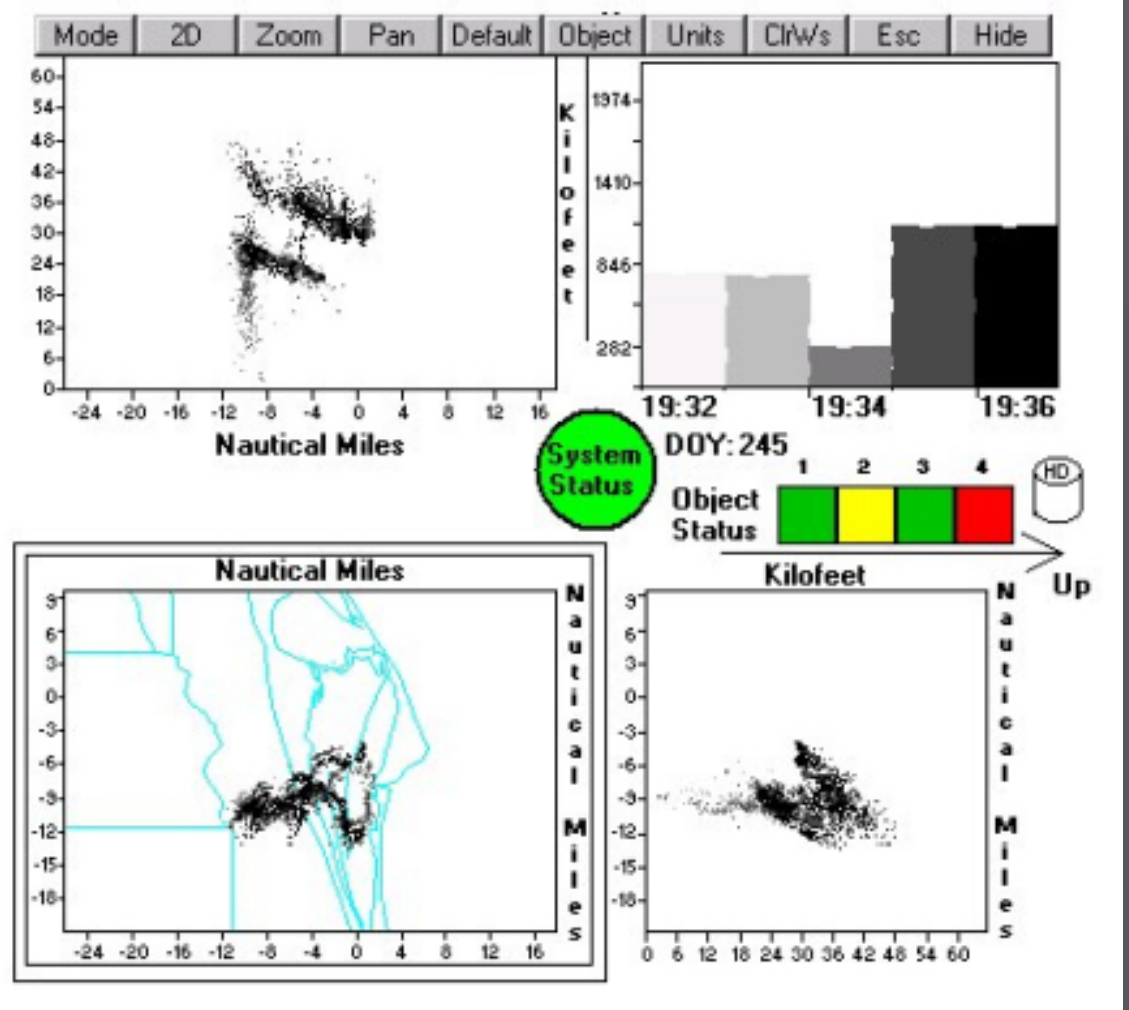

Upper LH - south view of activity at two altitudes, sloping from $\mathrm{W}$ to $\mathrm{E}$ Upper RH - time history of events Lower LH - activity viewed from above Lower RH - activity viewed from the E 
- Ground Operations

\section{Operational Impacts}

- The greatest lightning threat to space hardware is on the ground. Relocations from and to various processing facilities, from and to processing facilities and launch pads, and in recovery operations following landing all leave the hardware unprotected and exposed to cloud to ground lightning. This is because most, if not all space hardware is large, and moves quite slowly in transit. Thus, stringent move constraints must be employed in order to protect the hardware from lightning activity.

- For example, NASA Hardware move policies include weather constraints that preclude Orbiter towing operations during times when electrical storms threaten the area. Orbiter towing shall not commence if an electrical storm is within 5 nautical miles of the vehicle or conditions for potential electrical storm occurrence within 5 nautical miles of the vehicle are forecast for any period of travel of the vehicle. In the event that a lightning threat develops when the Orbiter is outside, then every practical effort is made to move the vehicle to a protected area.

- Similarly, even more stringent constraints are in place for movement of the entire stacked vehicle when it is moved to the launch pad, an operation that requires approximately 6 hours to complete. 
- Ground Operations

\section{Operational Impacts}

- External tanks are towed from the Michoud facility in Louisiana to KSC by one of two NASA recovery vessels, Liberty Star and Freedom Star. The tanks are stowed inside the Pegasus Barge for the trip.

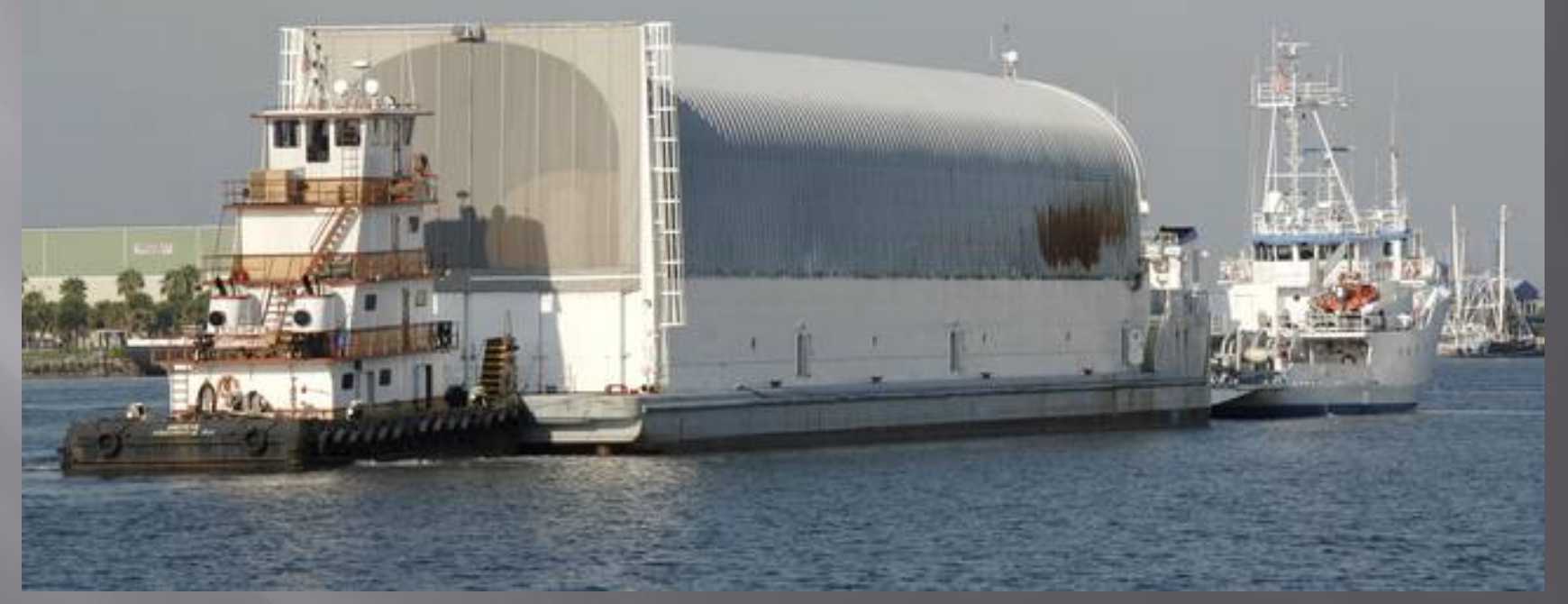

- The tanks are fully protected from lightning inside an all metal enclosure, including a closeout panel at the entryway to the interior. 


\section{Operational Impacts}

• Ground Operations

- Solid rocket booster segments are shipped to \& from the ATK facility in Utah to KSC by rail. The boosters segments are located inside a clamshell housing that provides full metallic coverage for protection from weather, including lightning attachments.

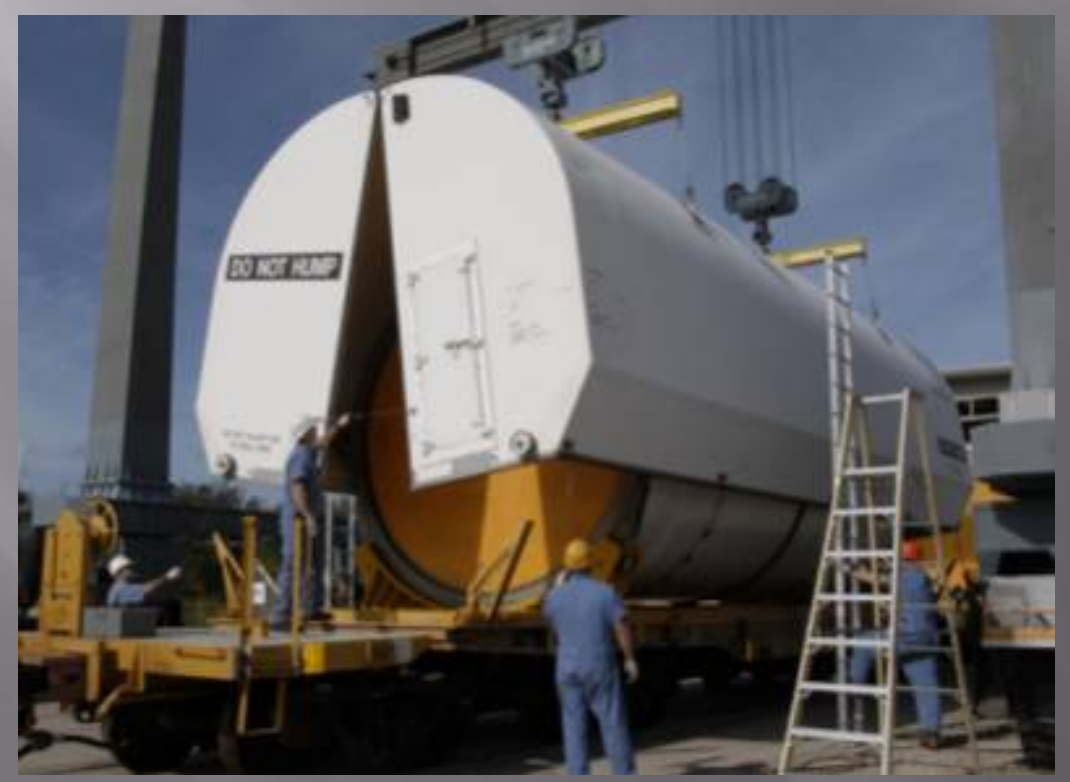

- Spaceport personnel are also at hazard from lightning activity. At KSC, a 2 phase advisory/warning policy is in force to protect personnel.

- A Phase 1 Advisory is issued when lightning is forecast within five nautical miles of the designated site with a desired lead-time of 30 minutes. The 30-minute warning gives personnel in unprotected areas time to get to protective shelter and gives those working on lightning sensitive tasks time to secure operations in a safe and orderly manner.

- A Phase 2 Warning is issued when lightning is imminent or occurring within five miles of the designated site. All lightning-sensitive operations are terminated until the Phase II Warning is lifted. 


\section{- Flight Operations}

\section{Operational Impacts}

- The second greatest lightning threat to space hardware is triggered lightning events during launch, followed closely by natural lightning, either during launch or during descent and landing. Apollo 12 and AC-67 were both struck by triggered lightning.

- NASA employs a large number of weather related constraints for launch activities. Similar restrictions govern the decision for re-entry burn, to make sure there are no unacceptable weather conditions present during descent or at the time of landing. Among the launch constraints are 14 rules governing lightning activity and the type and height of clouds in the area. As an example, 4 of these launch commit criteria are:

- Do not launch if lightning has been detected within 10 nautical miles of the pad or the planned flight path within 30 minutes prior to launch. Launch may occur if the source of lightning has moved more than 10 nautical miles away from the pad or the flight path and a field mill, used to measure electric fields, is located within 5 nautical miles of the lightning flash.

- Do not launch if lightning has been detected within 10 nautical miles of the pad or the planned flight path within 30 minutes prior to launch. Launch may occur if the source of lightning has moved more than 10 nautical miles away from the pad or the flight path and a field mill, used to measure electric fields, is located within 5 nautical miles of the lightning flash.

- Do not launch through an attached anvil cloud. If lightning occurs in the anvil or the associated main cloud, do not launch within 10 nautical miles for the first 30 minutes after lightning is observed, or within 5 nautical miles from 30 minutes to 3 hours after lightning is observed.

- Do not launch if the flight path will carry the vehicle through any cumulus cloud that has developed from a smoke plume while the cloud is attached to the plume, or for the first 60 minutes after the cumulus cloud detaches from the smoke plume. 


\section{Requirements}

- Lightning requirements for aerospace have been under constant development and improvement by multiple organizations for many years.

- Space Shuttle Lightning Requirements, JSC 07636, Baseline, was released in 1973

- $\quad$ NASA Reference Publication 1008, Lightning Protection of Aircraft, was released in 1977

- The AE4L Committee of the SAE published AE4L-78-1, the so-called "Blue Book", in 1978. This document contained the first comprehensive set of requirements for test waveforms and techniques for aerospace vehicles and hardware.

- Rev B of JSC 07636 was released in 1979

- The DoD released Mil-Std-1757 in 1980, their own version of test waveforms and techniques for aerospace vehicles, the content of which differed from that of AE4L-78-1.

- AE4L released AE4L-81-2, the so-called "Yellow Book", in 1981, as an update to the previous release.

- McDonnell Douglas released a study in 1982 that assumed CG lightning had an average magnitude of 20kA; the rest of the "lightning community" in the meantime was massing data supporting a much higher average, with peak magnitudes of 200kA

- In 1984, Rev C of JSC 07636 was released. The same year, the FAA released Advisory Circular AC 20-53A, detailing lightning protection techniques and requirements for the protection of fuel systems.

- In 1985, a companion document to JSC 07636, JSC 20007, was released. JSC 20007 provided detail on how the requirements in JSC 07636 were to be verified using analysis and test. 


\section{Requirements}

- In 1986, Rev D of NSTS 07636 was released. The same year, the DoD released Mil-Std1795, establishing acceptable protection methodologies and requirements for aerospace vehicles.

- In 1987, Rev A of JSC 20007 was released. The same year, AE4L released AE4L-87-3, the "Orange Book", to specifically address protection from indirect effects.

- JSC 20007 was updated by Change 2 in 1988, to incorporate new vehicle zoning information, and new internal magnetic field levels.

- Rev E of NSTS 07636 was released in 1990, following a complete review of the lightning protection design of the Shuttle. This release combined 07636 and 20007 into a single document, and updated the requirements commensurate with existing military and commercial standards for lightning design and protection. This release generated 44 waivers against the requirements, and the entire community was given 1 year to review and impact the changes.

- Also in 1990, the NASA Reference Publication was updated and released as a privately published document. This same document was immediately co-released by the FAA

- Rev F of NSTS 07636 was released almost exactly 1 year after Rev E. The 44 waivers were retired, and replaced by 21 exceptions to the requirements, effectively eviscerating the document.

- The EUROCAE and AE4L jointly released AE4L-97-4, the "Purple Book", in 1997, establishing the deign lightning environment and related test waveforms.

- The SAE has released most recently a comprehensive set of requirements, detailed in the SAE 54XX series of documents. These documents form the basis for the lightning requirements that have been adopted for the Constellation Program, and documented in CxP 70080 and CxP 70141. 


\section{Requirements}

- $\quad$ Direct Effects

- Any physical effects to the vehicle and/or equipment due to the direct attachment of the lightning channel and/or conduction of lightning current. This includes dielectric puncture, blasting, bending, melting, burning and vaporization of vehicle or equipment surfaces and structures. It also includes directly injected voltages and currents in associated wiring, plumbing, and other conductive components.

- Indirect Effects

- Lightning indirect effects may result when the electromagnetic fields produced by a direct strike to the vehicle induce voltage and current transients into the electrical/electronic equipment or components. Such transients may also be produced by electromagnetic field penetration into the vehicle interior or by structural IR (current times resistance) voltage rises due to current flow on the vehicle.

- Indirect effects can cause upset of or damage to electrical/electronic systems performing functions that can affect continued safe operation of the aircraft. The occurrence of damage or upset to unprotected electronic components is likely if adequate protective measures are not employed. 


\section{Requirements}

Current model for a severe negative lighting flash is shown below.

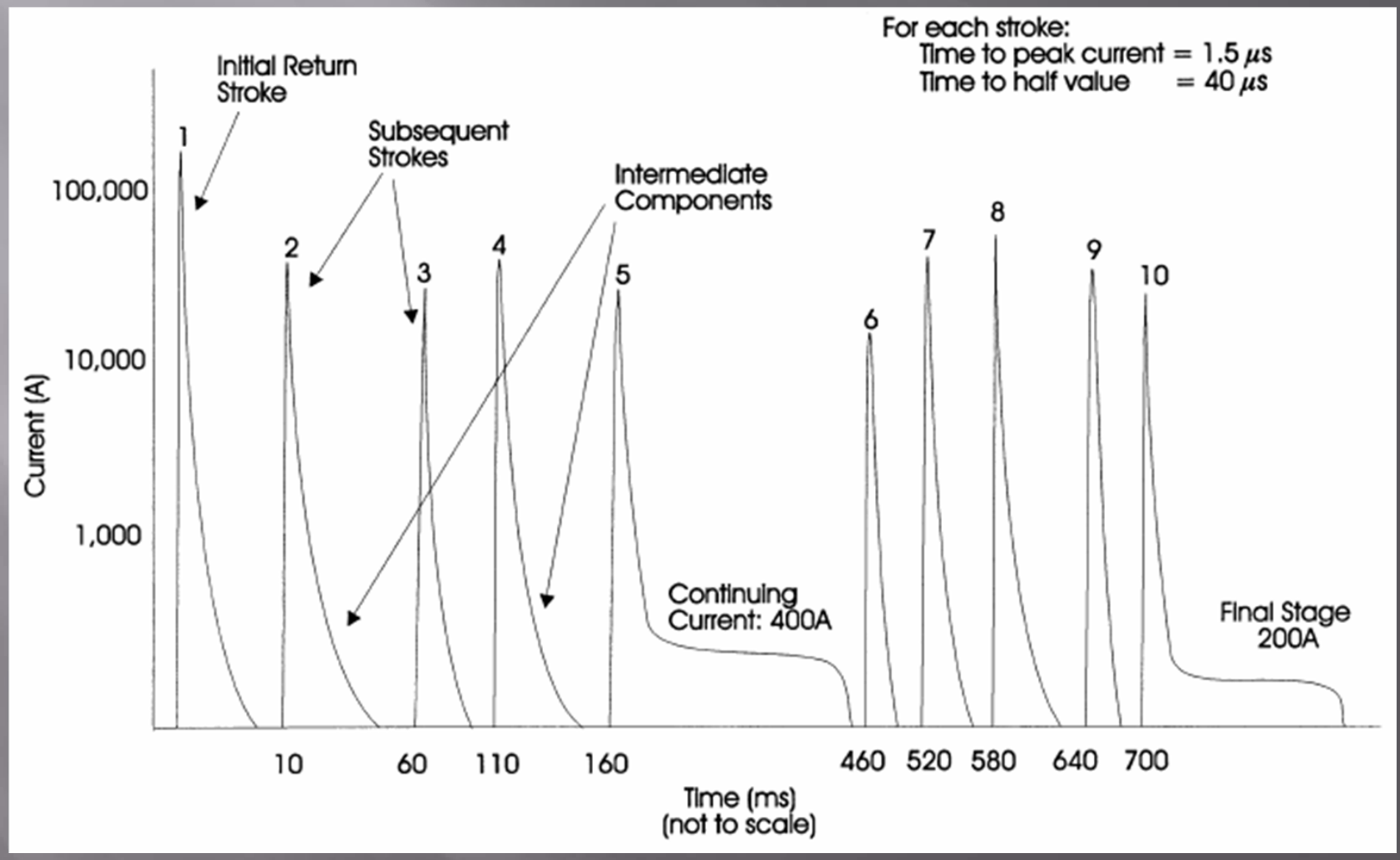




\section{Lightning Waveform Standardization}

- A Lightning Flash can be characterized by a compilation of standardized waveforms

- Alphabetic Designation: Characterizes waveforms (current components) of lightning strike (external)

- Component A-Initial High Peak Current

- Component B-Intermediate Current

- Component C-Continuing Current

- Component D-Restrike Current

- Component H-High Rate of Rise Current

- Multiple Stroke Waveform

- Multiple Burst Waveform

- Specific parameters of these waveforms can be found in SAE ARP 5412. 


\section{Lightning Waveform Standardization}

- External current components A, D, and H induce major transients internal to the vehicle

- Numerical Designation: Characterizes waveforms interior to the vehicle

- Transients are standardized and scaled down in amplitude according to electromagnetic region

- Waveform 1: Similar to current component A

- Waveform 2: The derivative of waveform 1

- Waveform 3: Resonating sinusoidal voltages and currents on cables

- Waveform 4: Structural IR voltages

- Waveform 5: Structural IR voltages and diffusion flux coupling

- Waveforms 1,2 and 3 are generally related to aperture coupling

- Waveforms 4 and 5 are related to structural IR effects and diffusion coupling processes

- Waveforms 3, 4, and 5 have been selected for use in indirect effects design and test for the CEV 


\section{Lightning Waveform Standardization}

- Natural lightning is difficult to reproduce in a laboratory environment with a degree of uniformity acceptable for certification purposes. So, various models of lightning have been developed over the years to aid in the understanding of the phenomenon, and to provide representative waveforms with controlled characteristics that can be faithfully reproduced.

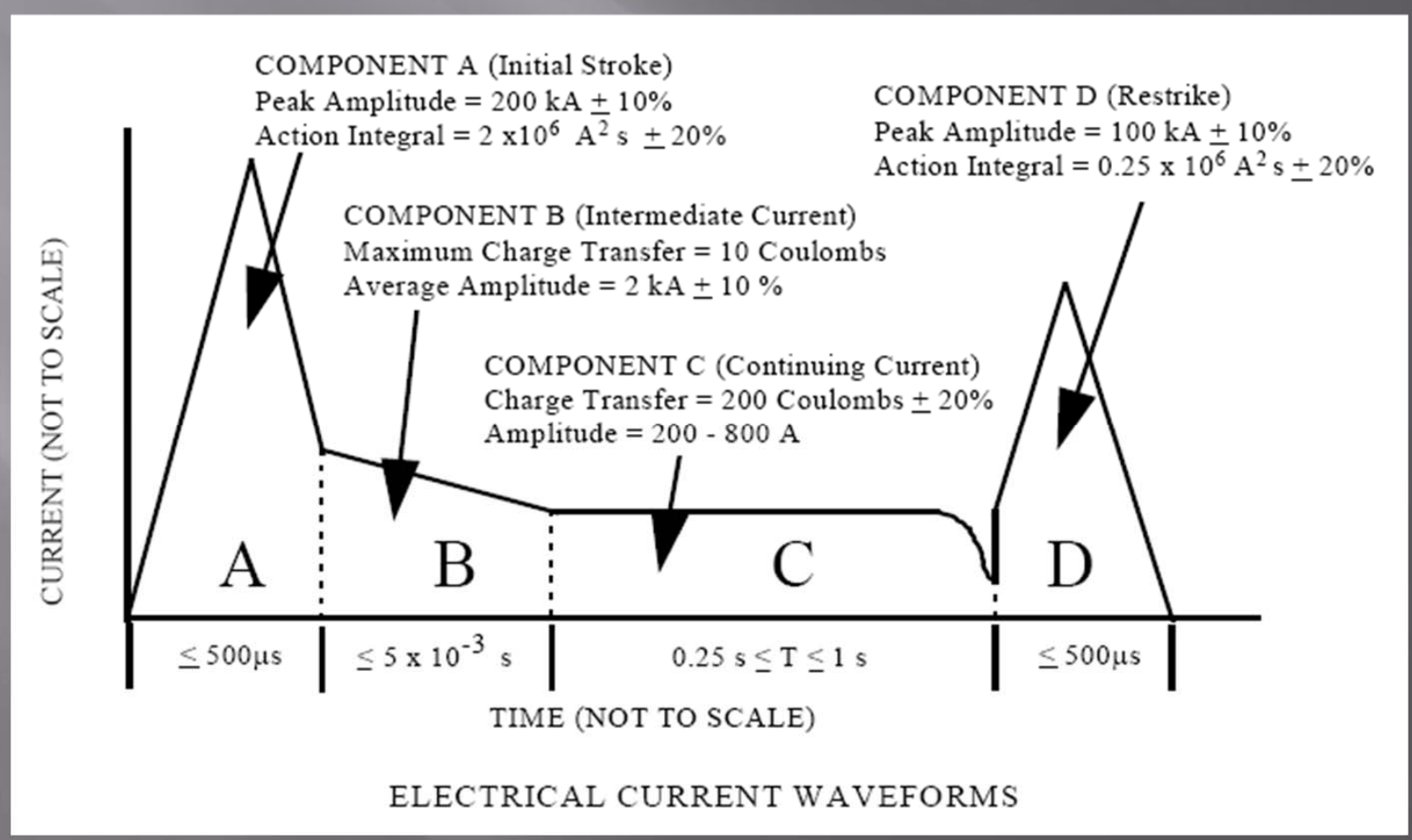




\section{Lightning Waveform Standardization}

$\underset{\text { peak }}{\mathrm{I}} 200 \mathrm{kA}$

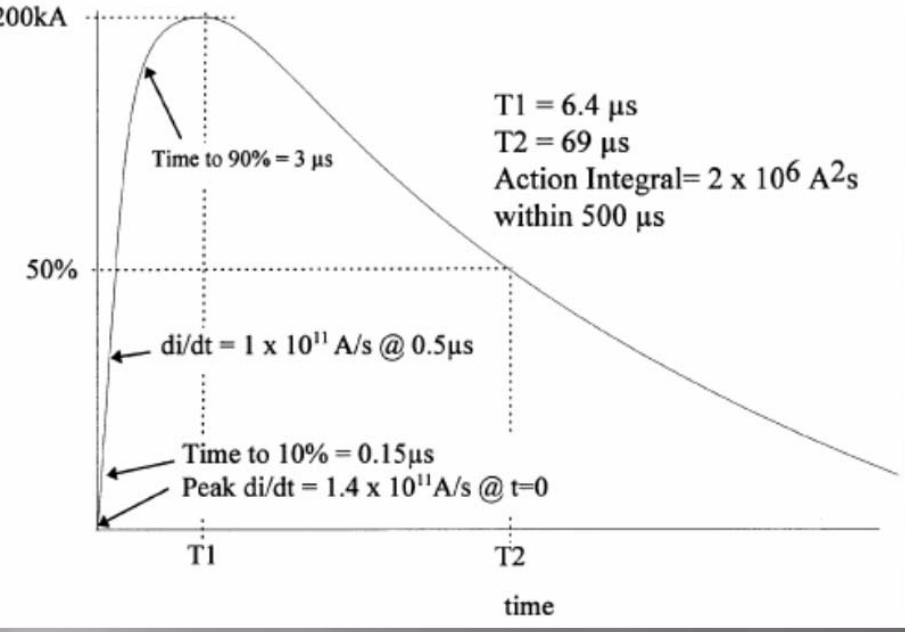

- Component Waveform B Intermediate Current: This component represents mainly the intermediate currents following some negative initial return strokes and/or restrikes
- Component Waveform A - First Return Stroke: This waveform combines the severe parameters of both negative and positive first return strokes. It occurs most frequently to aircraft flying at lower altitudes.

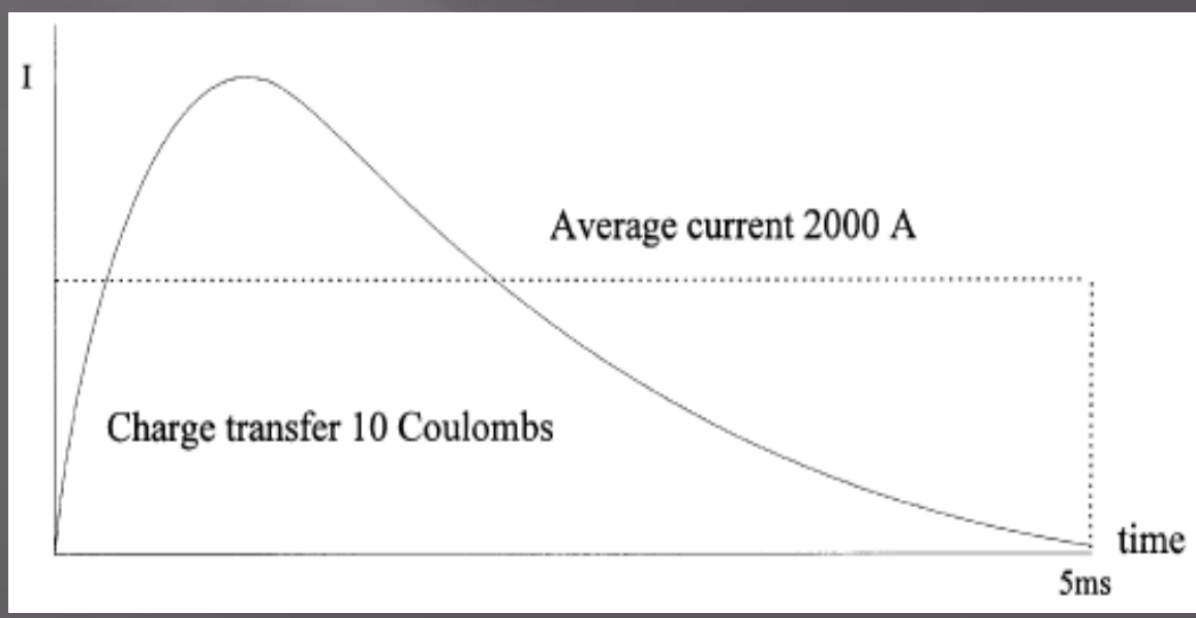




\section{Lightning Waveform Standardization}

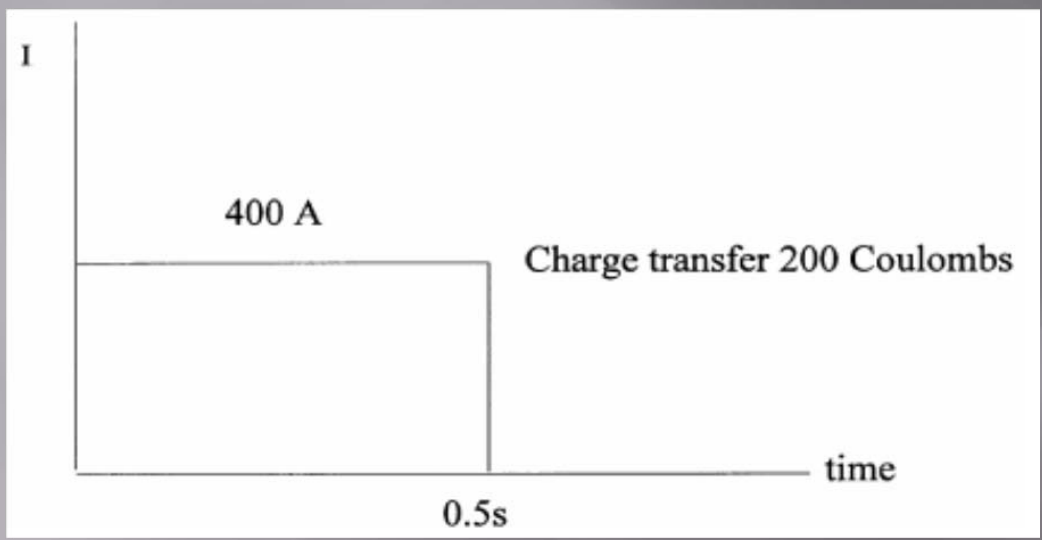

- Component Waveform D Subsequent Stroke Current: This waveform represents a subsequent stroke, and is the waveform used in the multistroke set. Used for both direct and indirect effects testing. The waveform version used for indirect effects testing is shown.
- Component Waveform C Continuing Current: This current component represents the lightning environment that might be caused by the long duration currents which may follow some restrikes of negative cloud to ground lightning strikes and also the return stroke of positive cloud to ground lightning flashes.

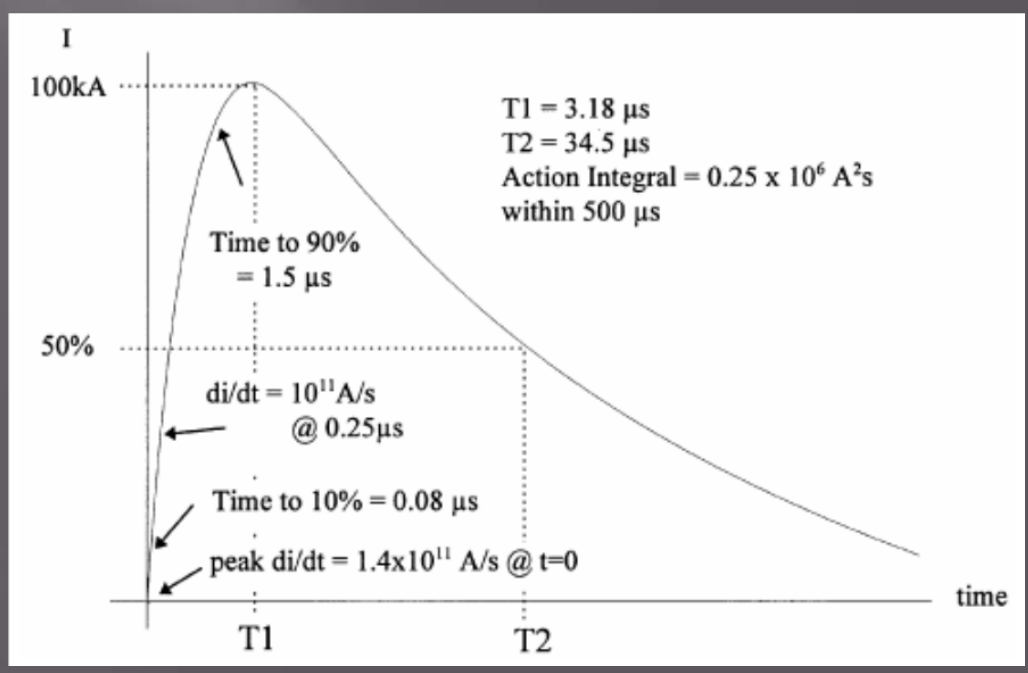




\section{Lightning Waveform Standardization}

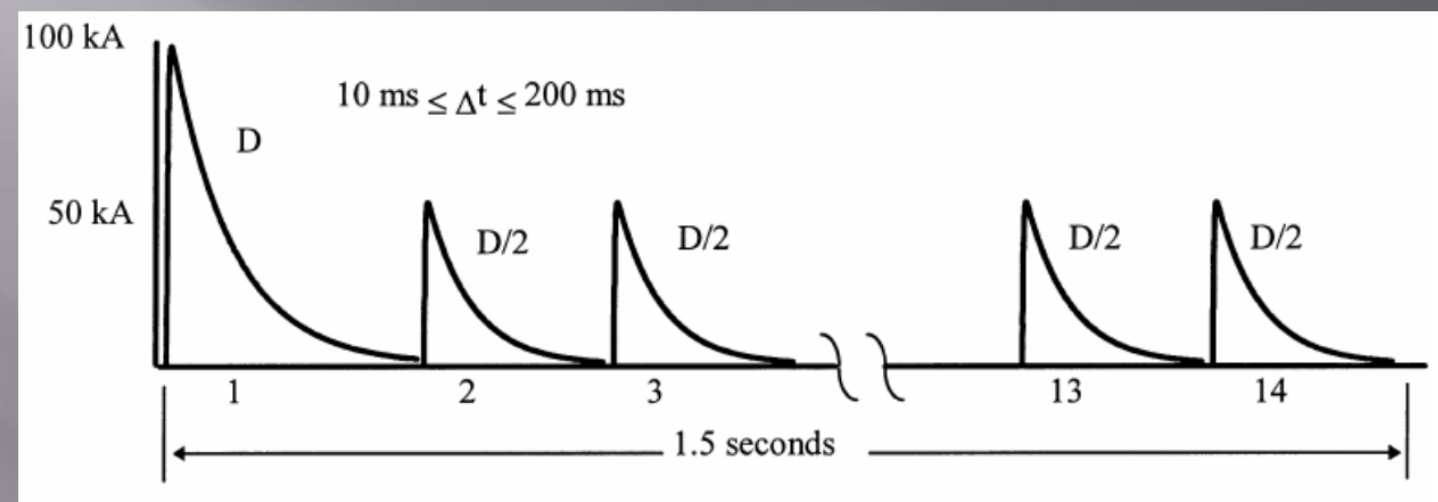

One current component $\mathrm{D}$ followed by thirteen current component $\mathrm{D} / 2 \mathrm{~s}$ distributed over a period of up to 1.5 seconds.

- Multi-Stroke Waveform Set: In many cases up to 14 randomly spaced strokes have been observed in negative cloud to ground flashes. Also several pulses of approximately $30 \mathrm{kA}$ can occur in a random sequence in an intra cloud event.

- The primary purpose of the Multiple Stroke Waveform set is to evaluate system functional upset of systems that may be susceptible to effects of multiple induced transients. 


\section{Lightning Waveform Standardization}
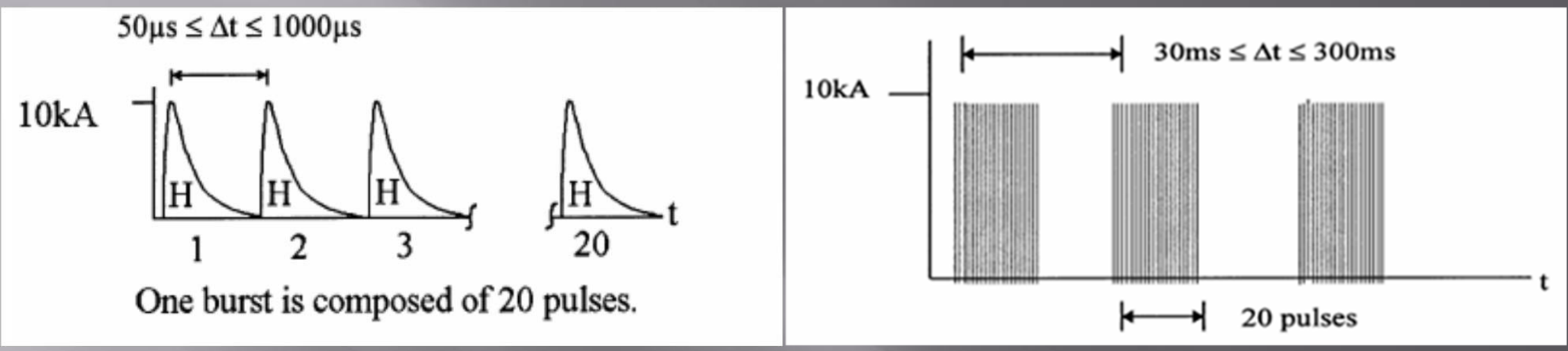

- Multi-Burst Waveform Set: The Multiple Burst Waveform set is comprised of component $\mathrm{H}$ waveforms. Component $\mathrm{H}$ represents a high rate-of-rise current pulse whose amplitude and time duration are much less than those of a return stroke. Such pulses have been found to occur in groups at the initiation of a lightning strike to an aircraft and randomly throughout the lightning flash duration, together with the other current components.

- The primary purpose of the Multiple Burst Waveform set is to evaluate system functional upset of systems that may be susceptible to effects of multiple induced transients. 


\section{Definitions of Interest}

- A couple of definitions are probably in order here.

- The first of these is the double exponential. $I_{t}=I_{0}\left(e^{-\alpha t}-e^{-\beta t}\right)$

- This is a deceptively simple transcendental equation used to describe many of the standardized waveforms. The constants, $\alpha$ and $\beta$, define the decay and rise times of the wave, respectively. The determination of these constants is not a straightforward process, and generally involves a seeded iterative routine.

$$
\begin{gathered}
I_{t}=I_{0}\left(e^{-\alpha t}-e^{-\beta t}\right) \\
\frac{d I}{d t}=0=I_{0}\left(-\alpha e^{-\alpha t_{1}}+-\beta e^{-\beta t_{1}}\right) \\
t_{1}=\frac{\ln (\beta / \alpha)}{\beta-\alpha}=\frac{1}{\alpha} \frac{\ln (\beta / \alpha)}{\beta / \alpha-1} \\
\frac{1}{I_{p k}}=I_{0}\left(-\alpha e^{-\alpha t_{1}}+-\beta e^{-\alpha t_{1}(\beta / \alpha)}\right) \\
\frac{I_{p k}}{I_{0}}=\left(-\alpha e^{-\alpha t_{1}}+-\beta e^{-\alpha t_{1}(\beta / \alpha)\left(t_{2} / t_{1}\right)}\right)
\end{gathered}
$$

- The peak magnitude of the waveform is found from the first derivative. The time $\mathrm{t}_{1}$ is the time at which the peak occurs.

- By definition, $t_{2}$ is the time at which the waveform has decayed to half of its peak magnitude value.

- $\quad$ Seed values are estimated by plotting the waveform using $t_{1}$ and $t_{2}$ for a given value of $\beta / \alpha$ that satisfies the $1 / 2$ magnitude relationship. 


\section{Deffinitions of Interest}

- The second definition of interest is the action integral.

- The action integral is given by: $A I=\int_{0}^{\infty} i^{2}(t) d t=\int_{0}^{\infty}\left[I_{0}\left(e^{-\alpha t}-e^{-\beta t}\right)\right]^{2} d t$

- The action integral allows us to calculate the amount of energy dissipated in resistive load, using the simple relationship

$$
W=A I \times R
$$

- Thus, the action integral is a mathematical description of the ability of the current to deposit energy in a resistive object, information that is critical to the determination of the immunity of the material or equipment under consideration. Standard analytical technique for calculations involving electronic circuitry uses this energy value in a process known as Wunsch-Bell analysis. 


\section{Wunsch- \\ Bell Analysis}

Wunsch-Bell analysis was developed to address the potential for exposure to nuclear electromagnetic pulse threats. The cornerstone of this analysis is the assertion that electronic components fail when subjected to levels of energy that cannot be dissipated safely by the component. Damage levels, and failure voltages and currents can be established for electrical and electronic components exposed to transient activity. A typical circuit is shown below, together with an equivalent circuit. Failure data is shown on the next page, and finally analytical calculations.

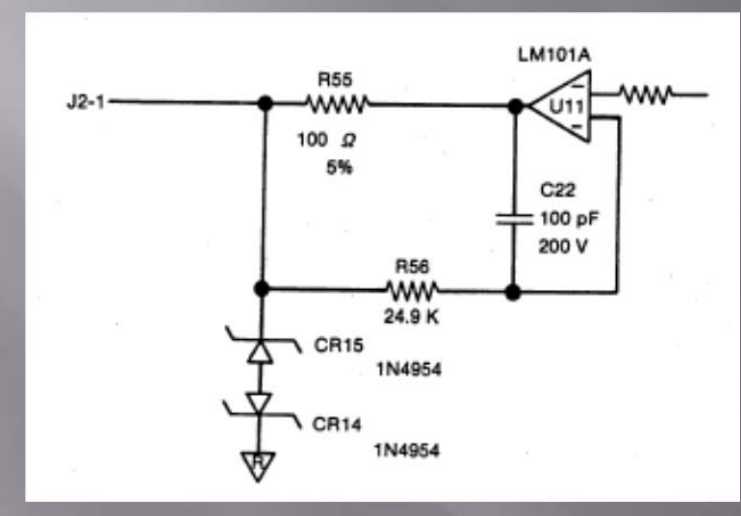

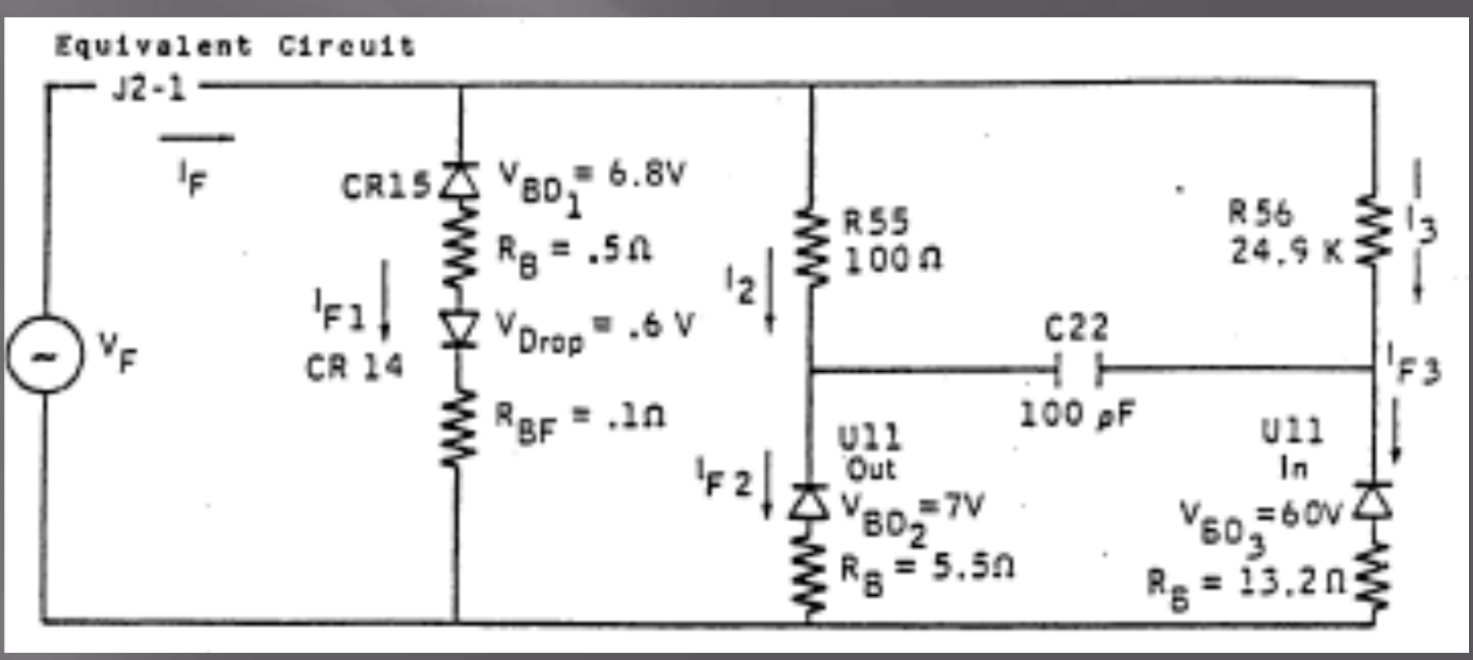

JSC Engineering Academy 


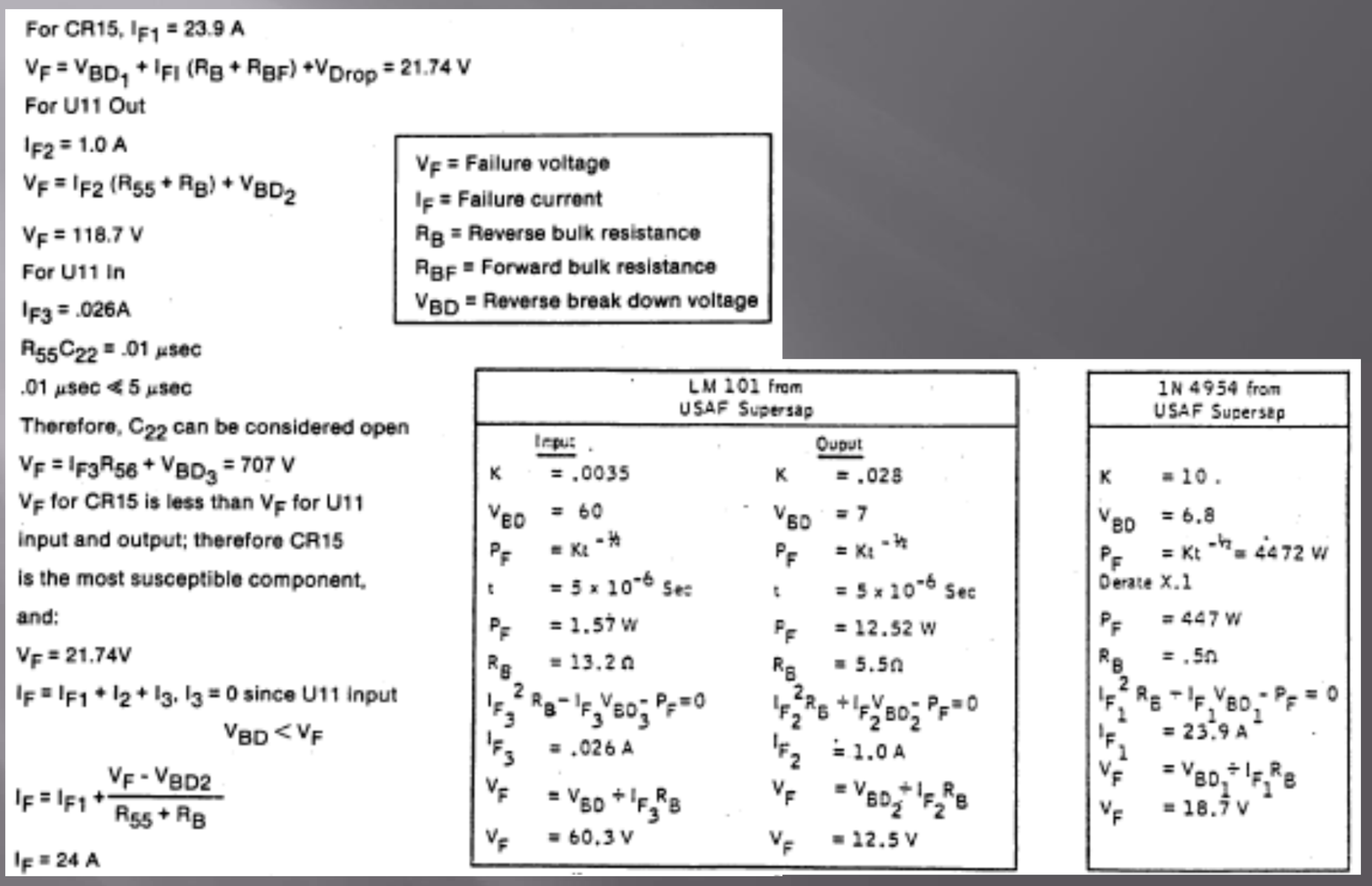




\section{Requirements}

Table 8 - Summary of Idealized External Lightning Current Component Parameters taken from SAE 5412A

\begin{tabular}{|c|c|c|c|c|c|c|c|}
\hline \multirow[t]{2}{*}{ Parameter } & \multicolumn{7}{|c|}{ Current component } \\
\hline & A & $A_{h}$ & B & $\mathrm{C}$ & D & $\mathrm{D} / 2^{1)}$ & $\mathrm{H}^{2)}$ \\
\hline $\mathrm{I}_{0}(\mathrm{~A})$ & 218,810 & 164,903 & 11,300 & 400 & 109,405 & 54,703 & 10,572 \\
\hline$\alpha\left(\mathrm{s}^{-1}\right)$ & 11,354 & 16,065 & 700 & N/A & 22,708 & 22,708 & 187,191 \\
\hline$\beta\left(s^{-1}\right)$ & 647,265 & 858,888 & 2,000 & N/A & $1,294,530$ & $1,294,530$ & $19,105,100$ \\
\hline$I_{\text {peak }}(\mathrm{A})$ & 200,000 & 150,000 & 4,173 & 400 & 100,000 & 50,000 & 10,000 \\
\hline $\begin{array}{c}\mathrm{di} / \mathrm{dt}_{\max }(\mathrm{A} / \mathrm{s}) \\
(\mathrm{t}=0+\mathrm{s})\end{array}$ & $1.4 \times 10^{11}$ & $1.4 \times 10^{11}$ & N/A & N/A & $1.4 \times 10^{11}$ & $0.7 \times 10^{11}$ & $2.0 \times 10^{11}$ \\
\hline $\mathrm{di} / \mathrm{dt}(\mathrm{A} / \mathrm{s})$ & $\begin{array}{l}1.0 \times 10^{11} \\
(t=0.5 \mu \mathrm{s})\end{array}$ & $\begin{array}{c}1.0 \times 10^{11} \\
(\mathrm{t}=0.375 \mu \mathrm{s})\end{array}$ & N/A & N/A. & $\begin{array}{c}1.0 \times 10^{11} \\
(\mathrm{t}=0.25 \mu \mathrm{s})\end{array}$ & $\begin{array}{l}0.50 \times 10^{11} \\
(\mathrm{t}=0.25 \mu \mathrm{s})\end{array}$ & N/A \\
\hline $\begin{array}{c}\text { action } \\
\text { integral }\left(\mathrm{A}^{2} \mathrm{~s}\right)\end{array}$ & $2.0 \times 10^{6}$ & $0.8 \times 10^{6}$ & N/A & N/A & $0.25 \times 10^{6}$ & $0.0625 \times 10^{6}$ & N/A \\
\hline
\end{tabular}

1) Applicable for the Multiple Stroke

2) Applicable for the Multiple Burst 


\section{Lightning Waveform Standardization}

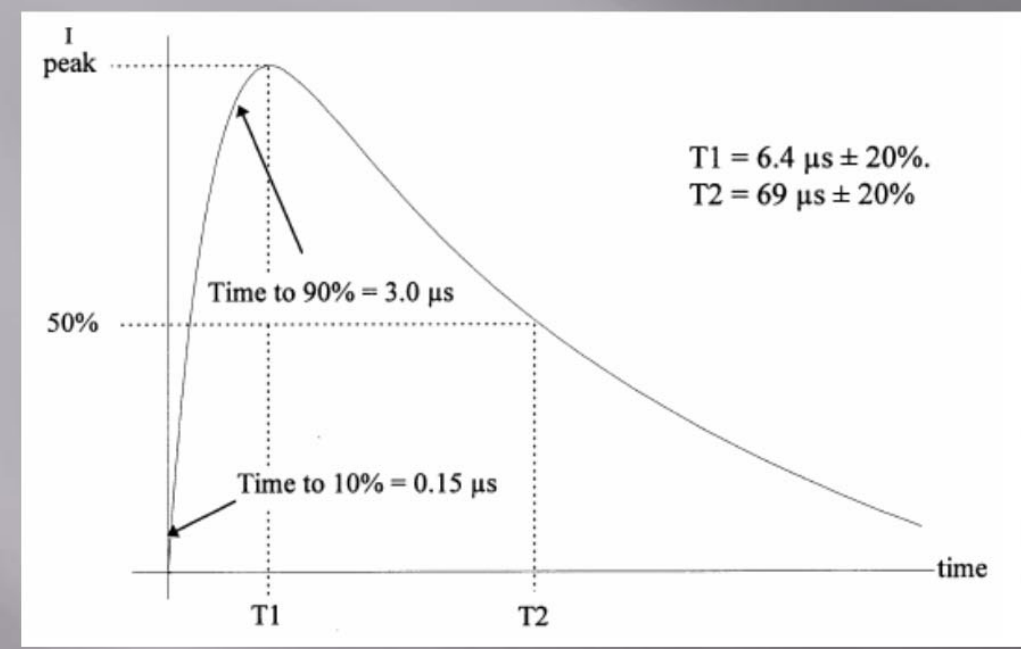

- Voltage Waveform 2 - Voltage whose waveshape is that of the derivative of the driving external environment Waveform A, found in loops existing between cables and the structure.
- $\quad$ Current Waveform 1 - Current(s) whose waveshape is that of the driving external environment Waveform A, found in conductors or shields terminated to structure through low impedances at each end.

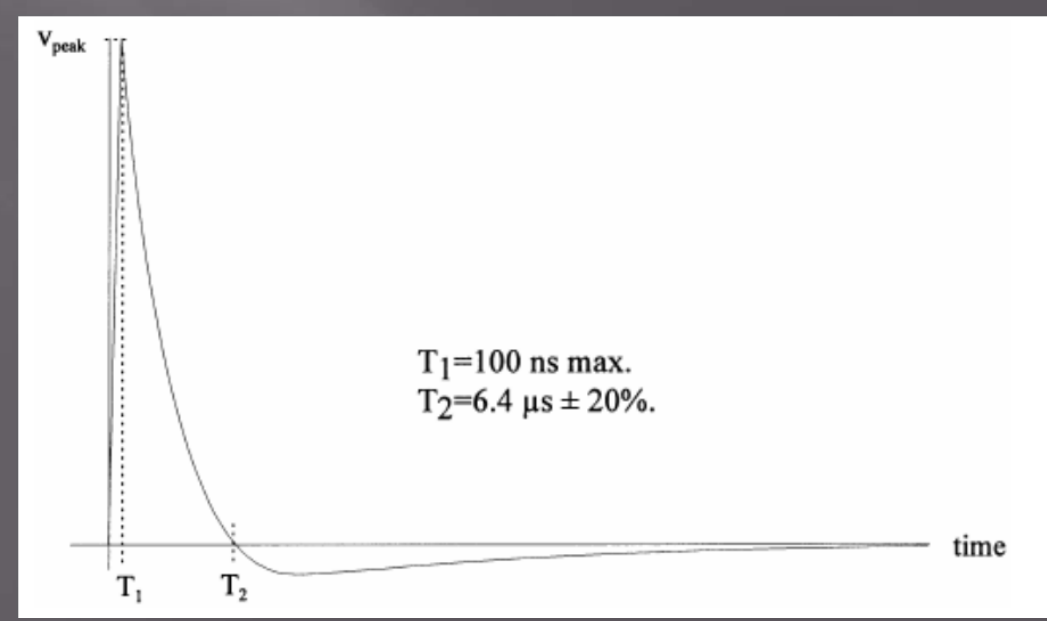




\section{Lightning Waveform Standardization}

- Damped Sinusoidal Voltage/Current Waveform 3 - Electric and/or magnetic fields penetrating through apertures will drive or excite resonance's on cables producing oscillatory currents and voltages which have the form of damped sinusoids. The frequency will be dependent on the structure length, and/or cable length and terminating components. Frequencies often range between 1 and $10 \mathrm{MHz}$; other frequencies outside this range have also been observed.

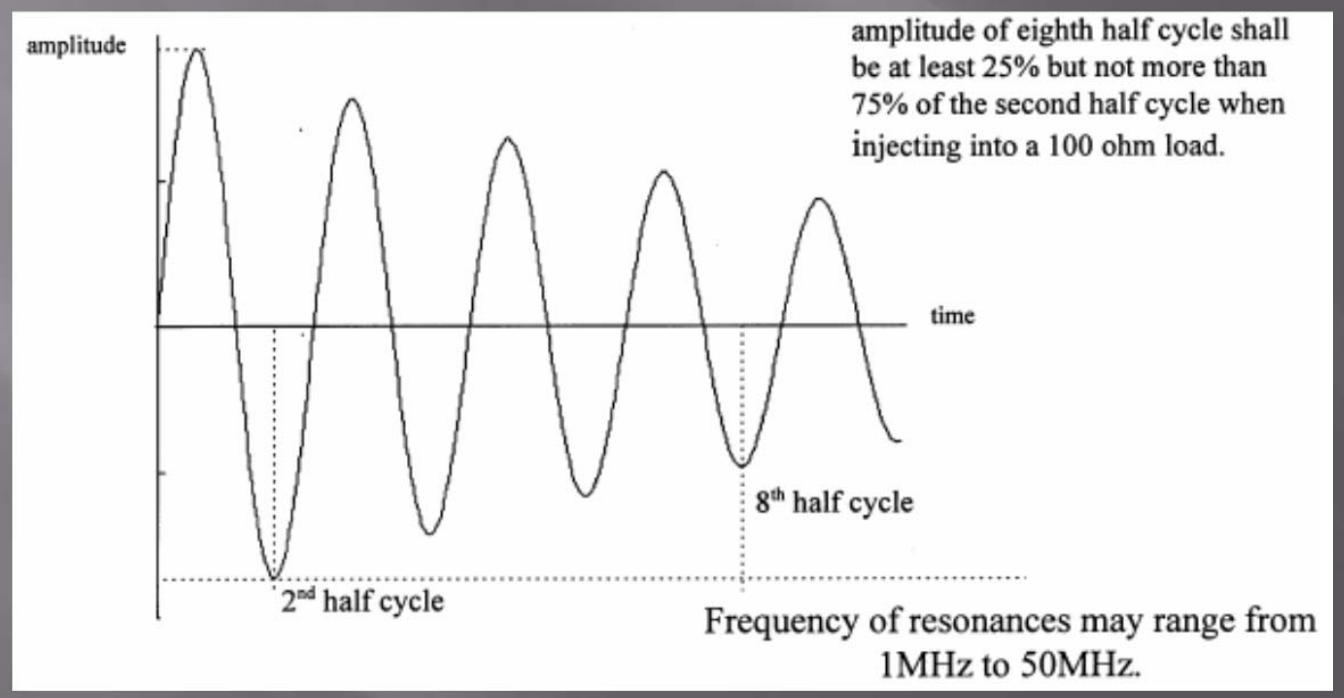




\section{Lightning Waveform Standardization}

- Voltage Waveform 4 - Voltages in loops existing between cables and the structure, which are the sum of the structural IR voltage between the end points of the cables and the voltage resulting from fields diffused through the structural materials. This is the most commonly seen transient waveform.

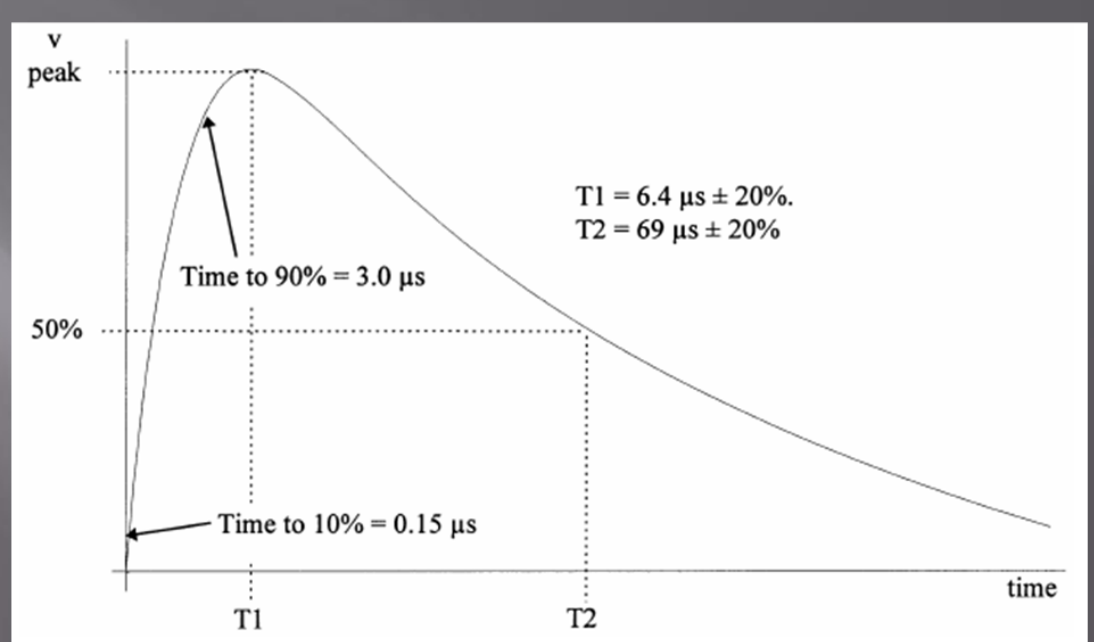




\section{Lightning Waveform Standardization}

- Voltage Waveform 5A \& 5B - The current in low resistance cables connected to structure at both ends involves a redistribution mechanism resulting from the relatively high inductance of the cable with respect to the structure. Inside an airframe made of a good conductor such as aluminum, the current will be long but of insignificant amplitude. For cables inside a more resistive structure of Carbon Fiber Composite (CFC) for instance, the current can have a lengthened double exponential Waveform and significant amplitude.
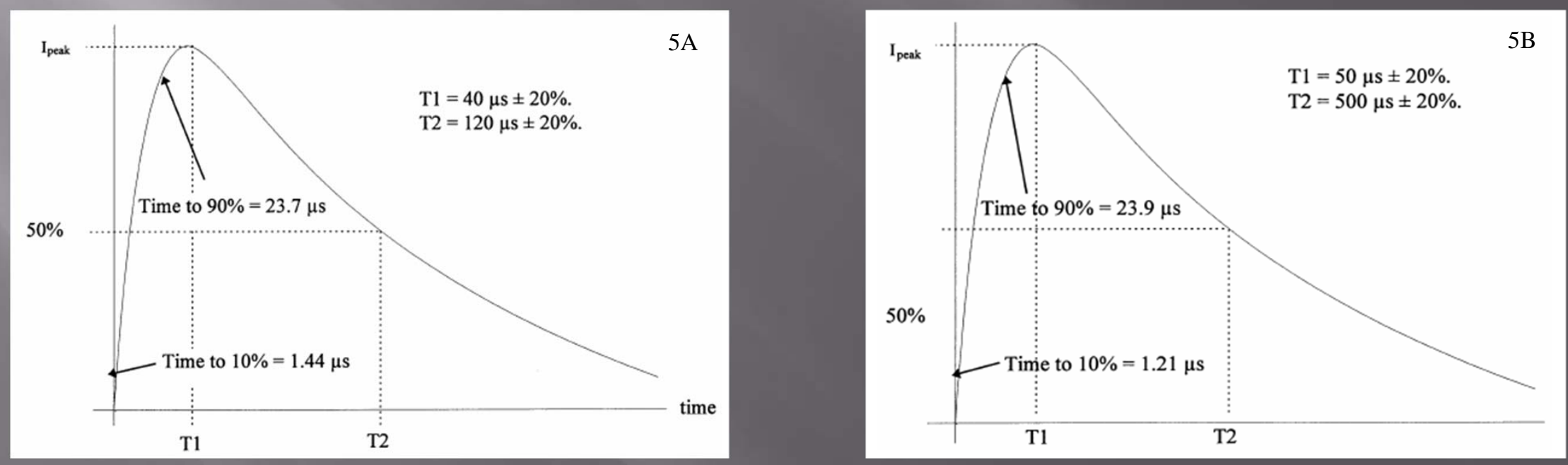


\section{Requirements}

Table 9 - Summary of Induced Transient Waveform Parameters, taken from SAE 5412A

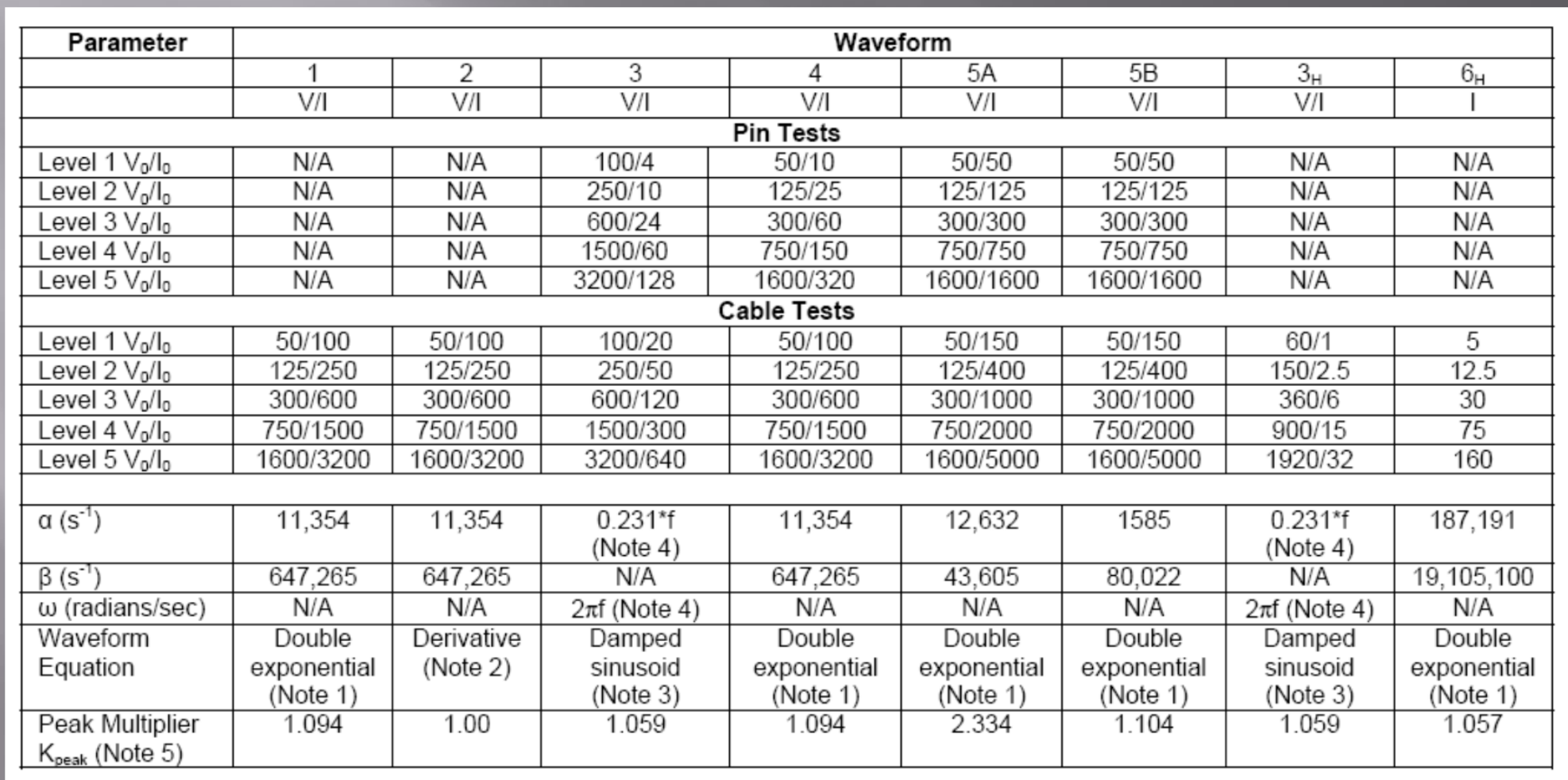

Note 1 Double exponential of the form $v_{t}=V_{0}\left(e^{-a t}-e^{-\beta t}\right)$ or $i_{t}=I_{0}\left(e^{-a t}-e^{-\beta t}\right)$

Note 2 Derivative of an exponential of the form $v_{t}=\beta e^{-\beta t}-\alpha e^{-\alpha t}$ or $i_{t}=\beta e^{-\beta t}-\alpha e^{-a t}$

Note 3 Damped sinusoid of the form $v_{t}=V_{0} \sin (\omega t) e^{-a t}$ or $i_{t}=I_{0} \sin (\omega t) e^{-a t}$

Note $4 \mathrm{f}$ is frequency in hertz

Note 5 The value of the peak multiplier is that which when multiplied by the peak threat level given above provides a value for $V_{0}$ or $I_{0}$ 


\section{Frect and Indirect Effects}

- The key to understanding the relationship between direct and indirect effects is to realize that internal transients are the result of exposure to external stimuli.

- Even if no direct attachment occurs, voltages and currents still will be induced inside vehicle elements. The magnitudes of such induced voltages and currents inside the vehicle are proportional to the magnitudes of the external environment, and are a direct function of the shielding afforded by the outer mold line.

- The external environment will couple into the vehicle via aperture and diffusion processes. Any breaks or seams that are not properly electrically bonded will allow penetration of electromagnetic fields. The higher the impedance or anisotropy of the outer mold line material, the greater the amount of current that will penetrate the vehicle via diffusion.

- It is important to realize that good electromagnetic shielding on the outer mold line of the vehicle is necessary to reduce the internal environment to a reasonable level, and that the degree of shielding for the outer mold line is very difficult to adjust. One either has shielding or one does not have shielding. 


\section{Direct Effects on Metal vs Composite}

- Metal surfaces

- isotropic, homogeneous, and highly conductive

- easily able to affect good quality electrical bonding across seams and gaps

- offer excellent shielding characteristics

- except for major strikes, surface damage is usually restricted to scorching and burning, accompanied by small pinhole punctures; may be more severe related to penetration through apertures

- damage is mostly caused by local heating, acoustic shock, and magnetic effects

- Composite surfaces

- anisotropic, inhomogeneous, and moderately conductive

- difficult to affect good quality electrical bonding

- moderate shielding characteristics without additional surface treatments

- without additional surface treatments, damage can be extensive even for moderate attachments, capable of producing large pits and complete penetrations through the OML

- damage is caused primarily by current flow through an irregular impedance leading to high local heating and entrapped gas expansion, as well as acoustic shock mechanisms seen with metal surfaces

- the simplest and most effective solution is to introduce a thin conductive layer in the OML, such as an expanded metal foil 
- Transparencies

\section{Other Direct Effects Considerations}

- May be damaged by acoustic shock, or local heating causing rapid gas expansion in between layers

- Electrical \& Electronic Systems

- Externally exposed electrical \& electronic components, antennas, wiring, and connectors may be severely damaged or destroyed

- may also serve as entry points for external voltages and currents into the interior of the vehicle

- Evaluation Test \& Analysis

- Generally performed on coupon samples of OML materials exhibiting representative assembly methods

- ARES is performing several tests on representative coupons of materials to be used for first and upper stage sections, as indicated

- Interstage - Frustum Composite-Metallic Joint Assembly - Qty 4

- US Interstage Composite Panel, 23"x 47" w/ TPS - Qty 2

- US Interstage Composite Panel, 22" x 22" - Qty 5

- US Interstage Composite Panel, 22" x 22" w/ TPS - Qty 2

- Mounting Stud Electrical Bonding Test Block Assembly - Qty 1

- Discussions within E3 support are recommending ORION leverage some of this information, and also perform additional testing for materials unique to the CM and SM, if necessary.

- May also be performed on electrical \& electronic components, antennas, wiring, and connectors that may be or are planned to be externally exposed 


\section{CEV OML Specifics}

- The CEV has a high impedance, highly anisotropic composite outer mold line (OML) material. With little or no additional shielding, internal circuitry and components would be exposed to potentially very high levels of induced voltages and currents as a result of external exposure to the lightning environment, irrespective of a direct attachment occurrence.

- Military and commercial aerospace communities have for decades been successfully building and operating composite aircraft to operate under the same requirements as levied against CEV, without huge and unreasonable mass/volume impacts to electrical and avionics systems.

- The technique that has been used very successfully by the military and commercial aerospace industries for decades for composite airframes is to add a thin layer of expanded metal mesh into the outer mold line of airframe segments prior to autoclave, then provide good structural and electrical bonding for those segments upon assembly.

- This technique has been implemented for the CEV CM and SM. 


\section{Indirect Effects Considerations}

- Determine the amplitude and waveform of the current and electromagnetic fields external to the vehicle.

- Determine the structural IR voltages and the internal electromagnetic fields.

- Determine the response of the wiring of the vehicle to those voltages and fields. That is, determine the voltages and currents induced on the wiring.

- Determine the response of electrical and electronic equipment to the induced voltages and currents, identifying that equipment that is susceptible to either upset or damage.

- Design and incorporate protective measures.

- Conduct testing to validate the immunity level. 


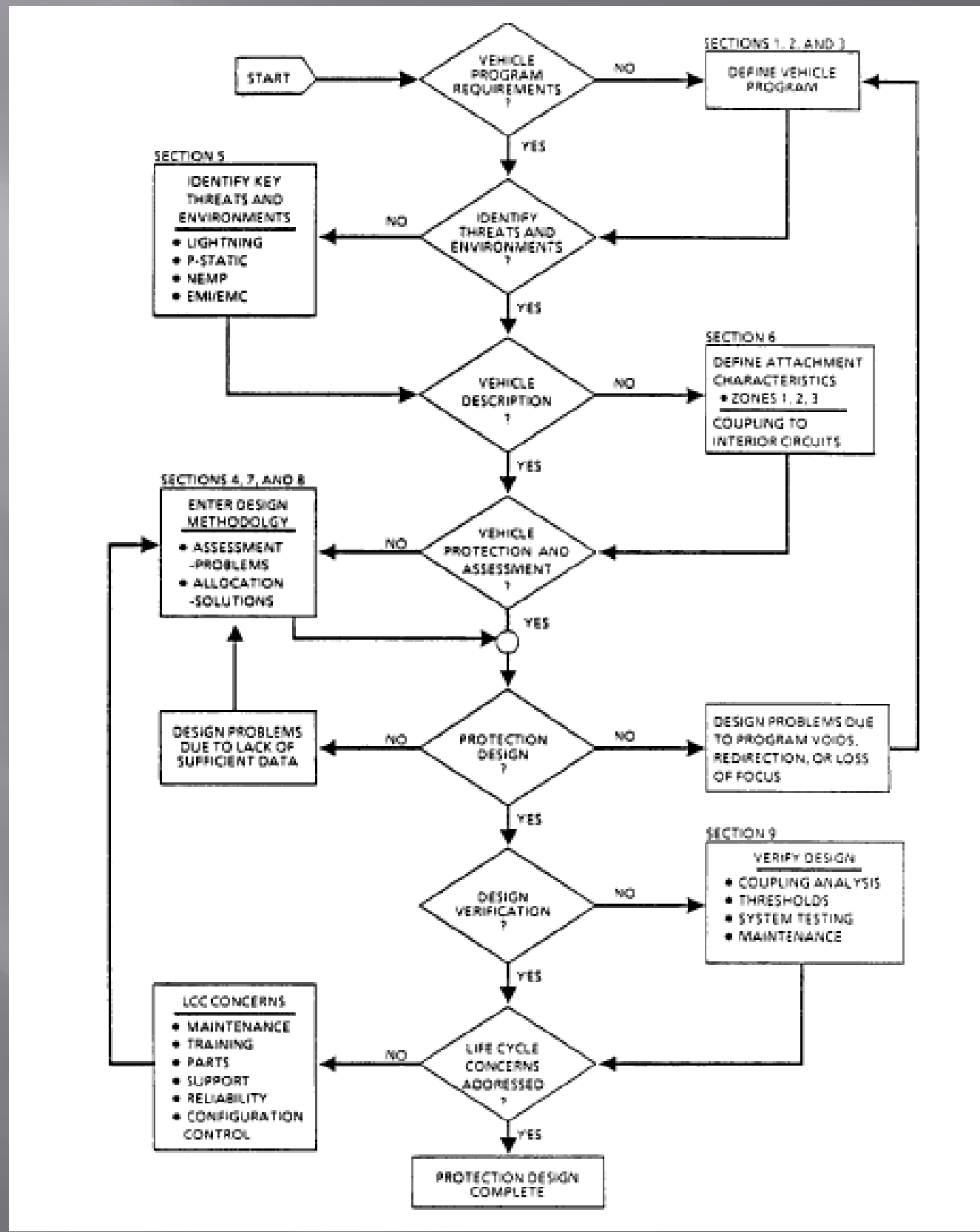




\section{Indirect Effects Considerations}

- Three coupling mechanisms are Structural IR, Magnetically Induced Voltages, \& Capacitively Generated Currents

- Structural IR

- This is the electric field created inside the vehicle by the voltage rise associated with the passage of external currents over the OML, typically across seams and joints. The voltage rise may be caused by a an easily identifiable resistance, but much more often is associated with a distributed impedance that is frequency dependent.

- The term voltage rise is used because in this case, we are interested in treating the voltage as a source of interference.

- Magnetically Induced Voltages

- These voltages are the result of aperture coupling into openings in the OML, or diffusion coupling through the OML itself. Magnetically induced voltages arise from Faraday's Law, and manifest themselves in the interior of the vehicle as either open circuit voltages or short circuit currents.

$$
V_{O C}=I \frac{\mu_{0} d H}{d t}=-\frac{d \phi}{d t} \quad I_{S C}=\frac{1}{L} \int V_{O C} d t
$$




\section{Indirect Effects Considerations}

- Capacitively Generated Currents

- These currents are also the result of aperture coupling, but this time it is directly coupled electric fields that engender the response. Apertures in this case include transparencies or other direct paths through the OML that have no, or very little, electromagnetic shielding.

$$
I_{S C}=I \frac{\varepsilon_{0} d E}{d t}
$$

- Methods of Determination of the Magnitude of Indirect Effects

- Analysis, including the Rolling Ball Method, and Numerical Modeling

- Measurements

- Inject CW ac currents into the vehicle, measure the frequency domain response, and apply Fourier Transform techniques to translate the results into the time domain.

- Inject full threat level pulse currents into the vehicle, and measure the time domain response.

- Inject low threat level pulse currents into the vehicle, measure the time domain response, and extrapolate the response to the full threat level. This is the technique that will be used for the CEV CM and SM at the Plumbrook facility during vehicle certification. 
- Rolling Ball Method

\section{Rolling Ball Method}

- The rolling ball, or sphere, method was developed by Professor Horvath at the Technical University of Budapest in 1962. The theory is based on two assumptions:

- The point of strike of lightning is determined when the downward leader approaches the earth or a structure within striking distance

- Lightning strikes the nearest earth object from the orientation point and so its worst position is the center of a sphere that attaches to several earth objects.

- Given these assumptions are true, then the conclusion is that lightning will not attach to an object if its striking distance is greater than the radius of the sphere.

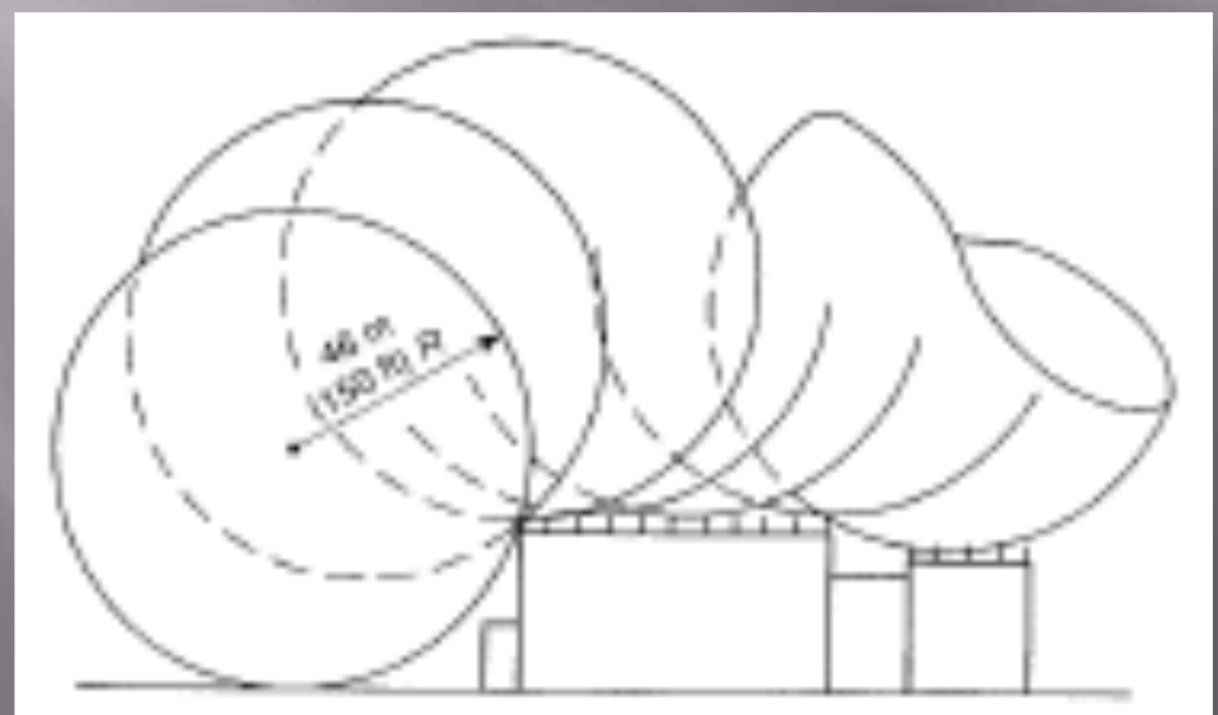

- While the method was originally developed to address facilities on the ground, it has been widely adopted for aerospace vehicle zoning analysis for many years.

- Recent applications within NASA include analysis associated with zoning for the CEV CM \& SM, and the new lightning protection towers at Pad 39B at KSC. 


\section{Spectral Content}

- As a part of analysis for direct \& indirect effects, knowledge of the spectral content of the applied waveforms can be used to good advantage when searching for susceptible hardware.

- The parameters of current component A are shown, together with a Bode plot of the spectral content indicating the break point frequencies.

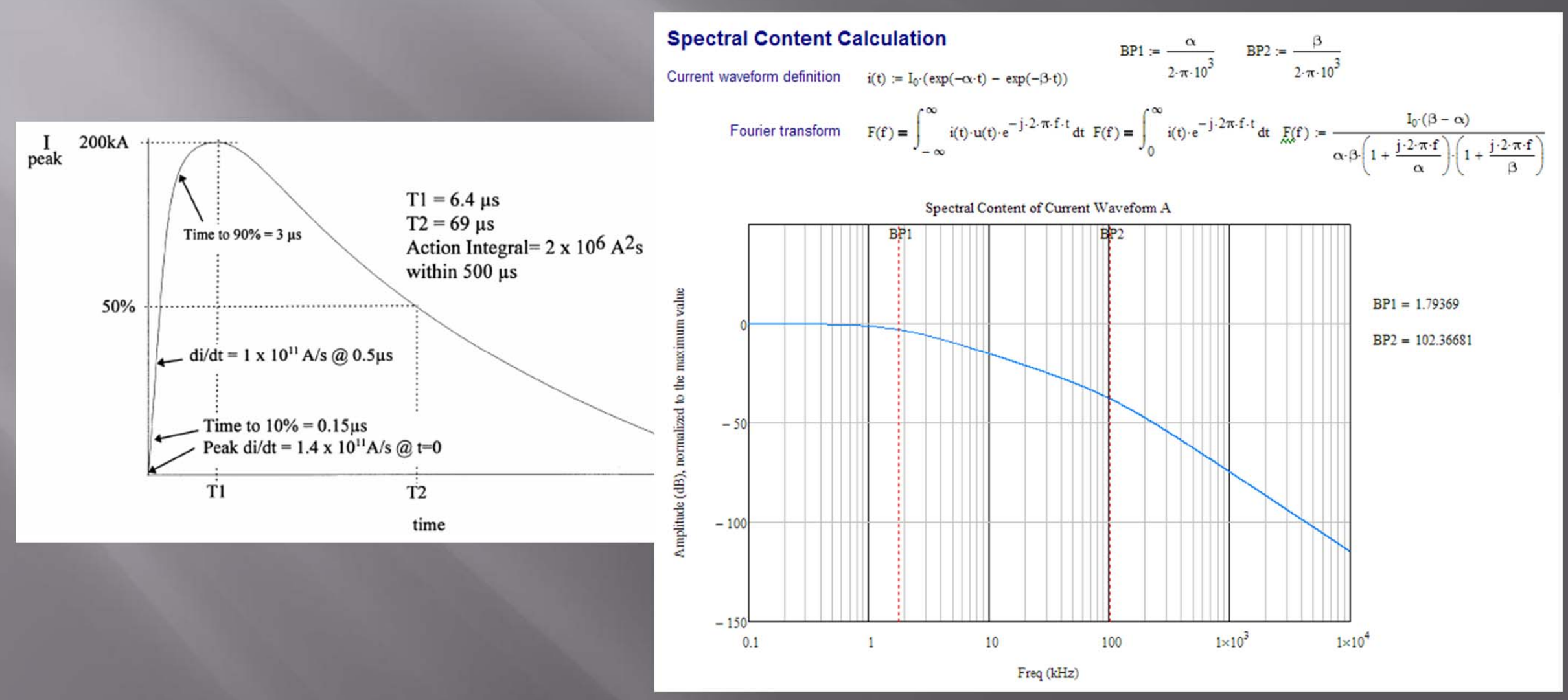




\section{uipment Transient Design Levels \& Margins}

- When analyzing for indirect effects, margins are naturally a concern. The diagram below illustrates the approach to be used in the establishment of design levels for the desired margins.

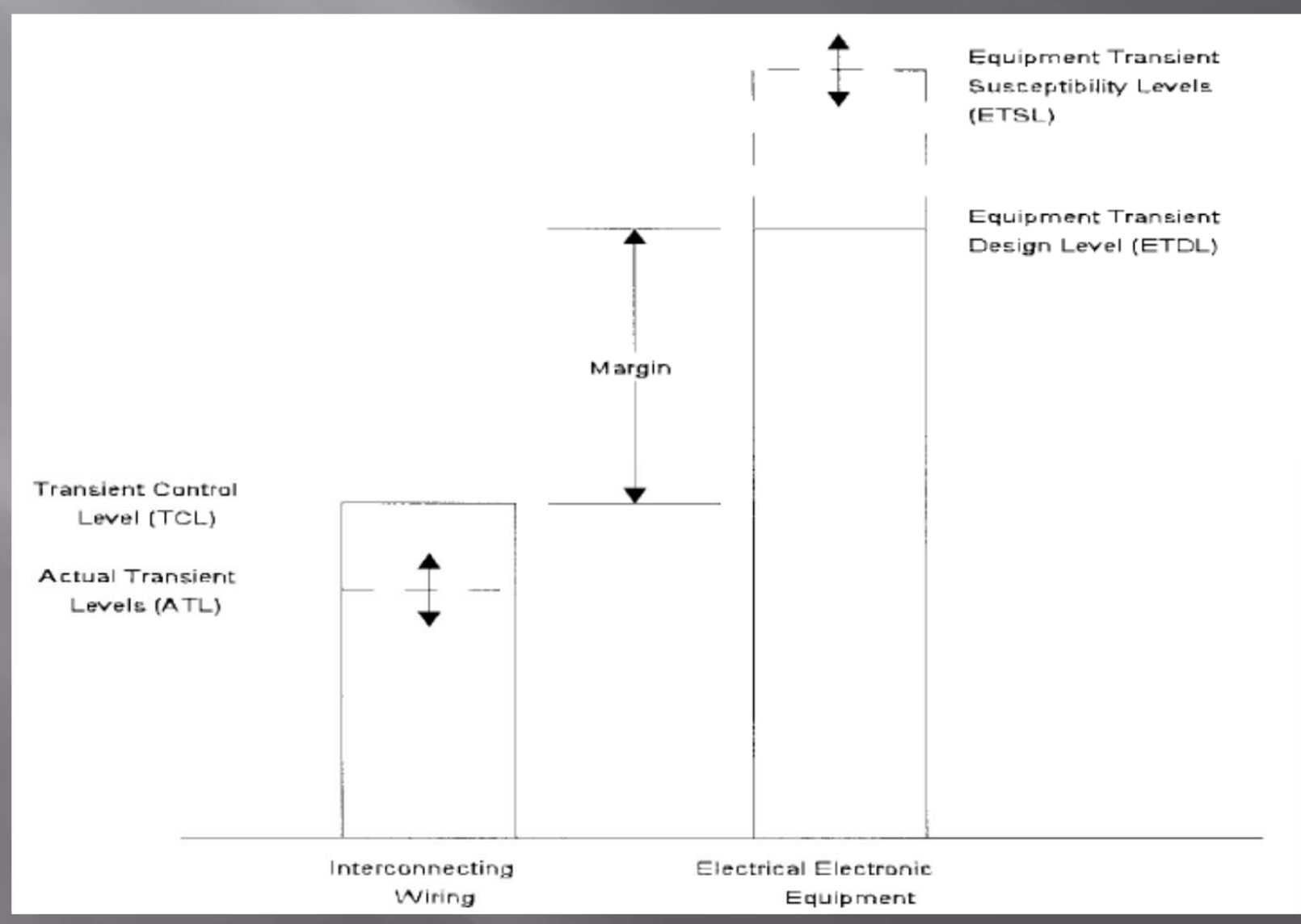




\section{Tuipment Transient Design Levels \& Margins}

- Transient Control Levels (TCL) and Equipment Transient Design Levels (ETDL) need to be established for a robust design. ETDLs represent the amplitude of voltage and/or current that the equipment is required to withstand or tolerate and remain operational (e.g., no damage or system functional upset). TCLs are set equal to or higher than the maximum Actual Transient Level (ATL). The difference between ETDL and TCL is the margin. Equipment Transient Susceptibility Level (ETSL) is the amplitude of voltage or current which, when applied to the equipment, will result in damage to components, or upset such that the equipment can no longer perform its intended function.

- The ETDL is usually stated in the specifications for electrical/electronic equipment and constitutes a qualification test level for the equipment. Since ETDLs are typically represented by these standardized requirements, their use greatly simplifies compliance evaluation. Normally, TCLs and ETDLs will be established by the vehicle contractor or system integrator, who will compare the penalties of vehicle or interconnecting wiring protection or equipment hardening to establish the most logical combination of TCLs and ETDLs. 


\section{CEV CM \& SM Low Level ning Test Configuration}

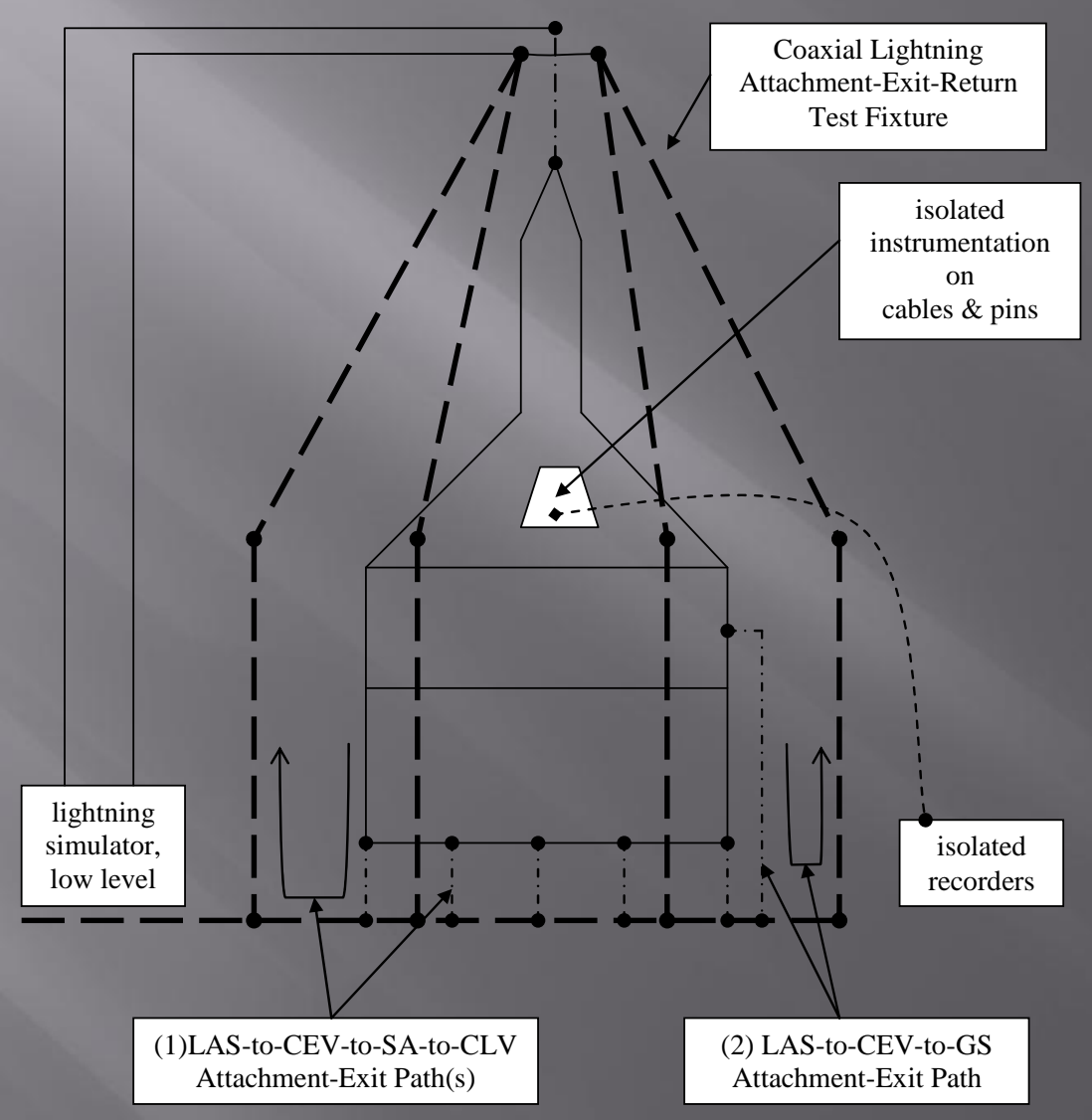




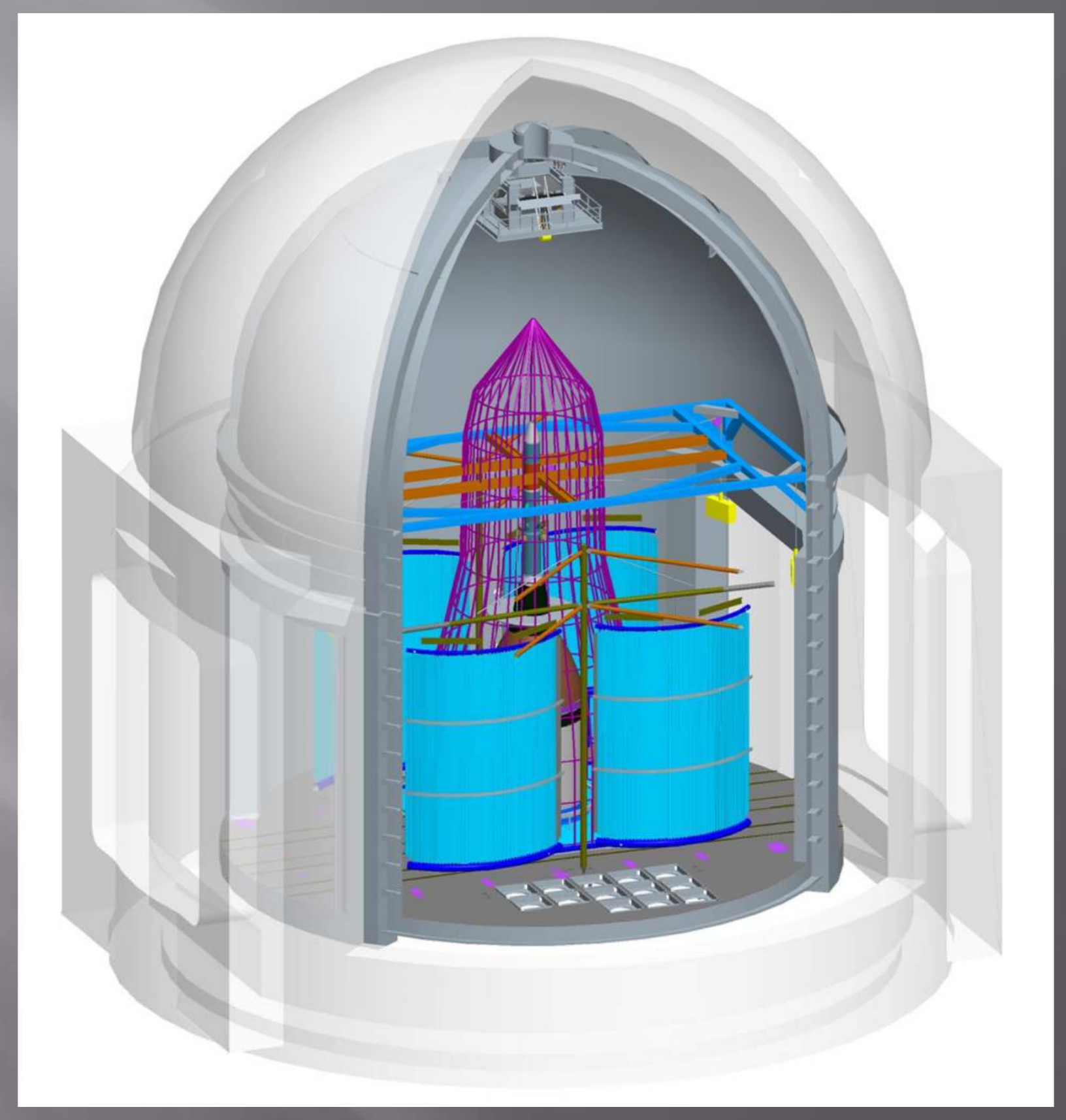




\section{Protection Design}

- Protection design is a logical process, and moves through a series of steps. Zoning the vehicle is the starting point, followed by definition of both the external and internal lightning environments. Once this has been accomplished, the next step is to identify critical hardware, and using the known immunity levels of that hardware, establish the protection criteria for the design.

- Zoning

- Zoning is the process of determining where lightning is most likely to attach to the vehicle, and in what manner. It may attach and hang on at the attachment point, or it may sweep across the vehicle surface.

- 5 zone categories have been identified. They are:

- Zone 1A - initial attachment point with low possibility of channel hang-on

- Zone 1B - initial attachment point with high possibility of channel hang-on

- Zone 2A - swept-stroke zone with low possibility of channel hang-on

- Zone 2B - swept-stroke zone with high possibility of channel hang-on

- Zone 3 - intermediate areas that may carry substantial amounts of conduction current between zones 1 and 2. 


\section{Protection Design}

- As an example, p/o the Orbiter vehicle zoning is shown below.

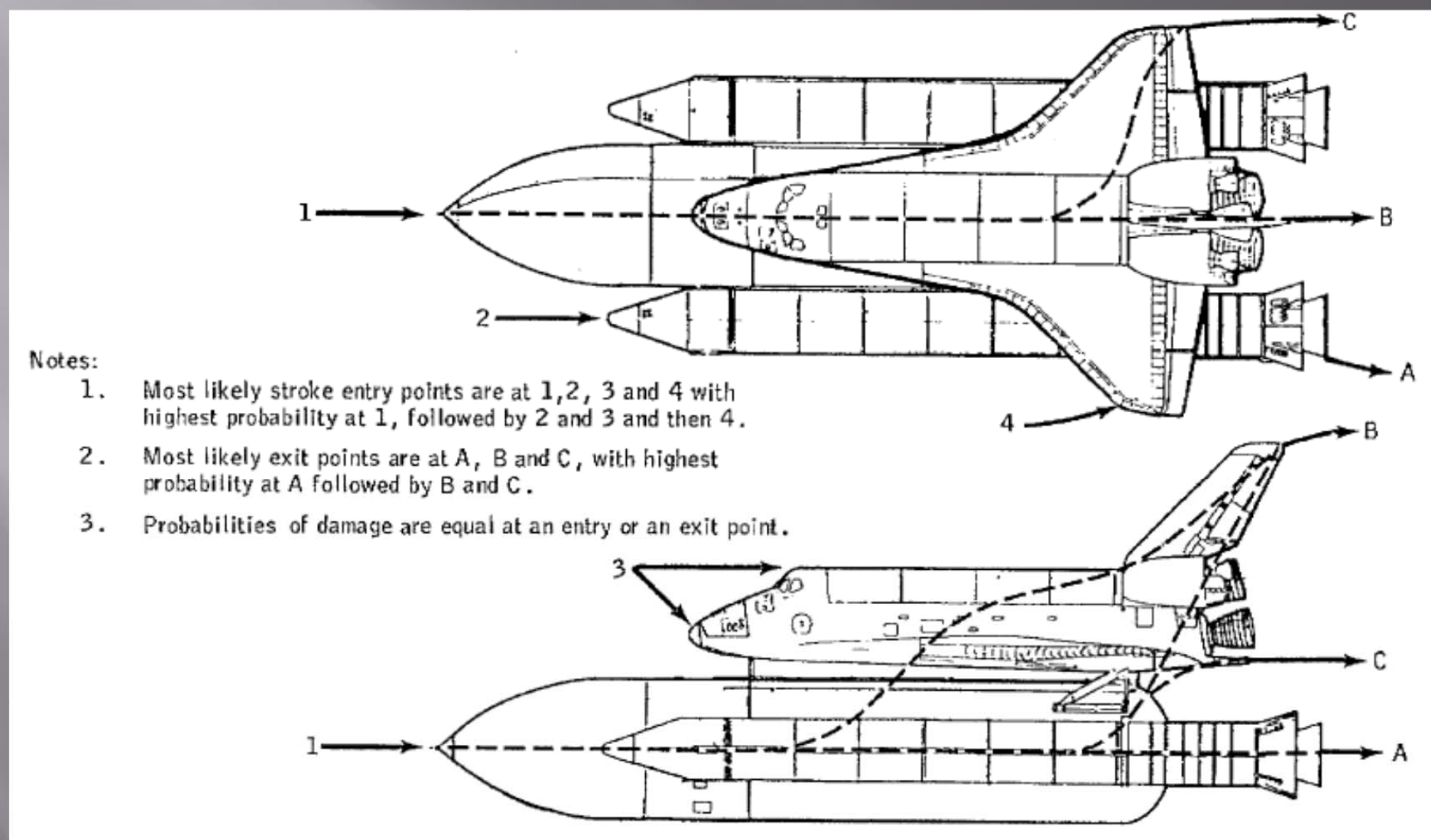

Figure 2-1.- Anticipated lightning stroke entry and exit points for composite shuttle vehicle during the launch phase. 


\section{Protection Design}

- Another example, zoning for a transport class aircraft (p/o Fig. 8 in SAE ARP5414A)

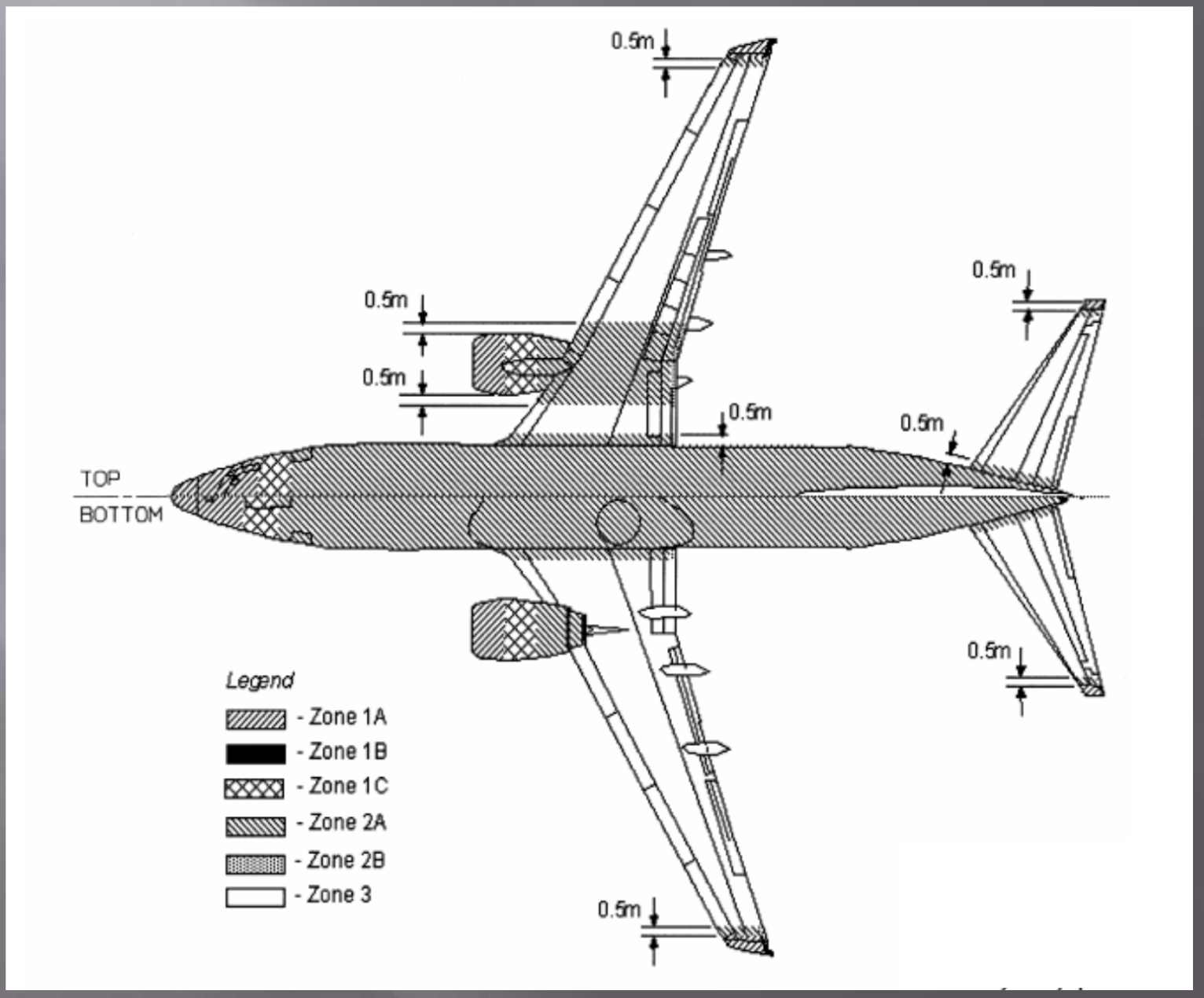




\section{Protection Design}

- Lightning Environment Definition

- Based on the zoning, and the stated requirements for the vehicle in terms of threat levels, operational phases, and so forth, the various external waveforms can be associated with the various zones. The vehicle structure is then reviewed for the presence of apertures, joints, seams, the use of metals versus composites, the lengths, types, and locations of wiring, the locations of equipment, and the shielding used on the wiring and equipment enclosures. From this review, a starting point for the internal environment can be established using a specific tailoring approach to the levels shown earlier in Tables $8 \& 9$ as shown in the Requirements section of this briefing.

- Such a tailoring process was implemented during design efforts for the Cockpit Avionics Upgrade, and the resulting levels were placed into documents for subsequent design and test efforts.

- An extract from SAE ARP 5415 is shown next as a means of providing a more detailed explanation of the process. 


\section{Protection Design}

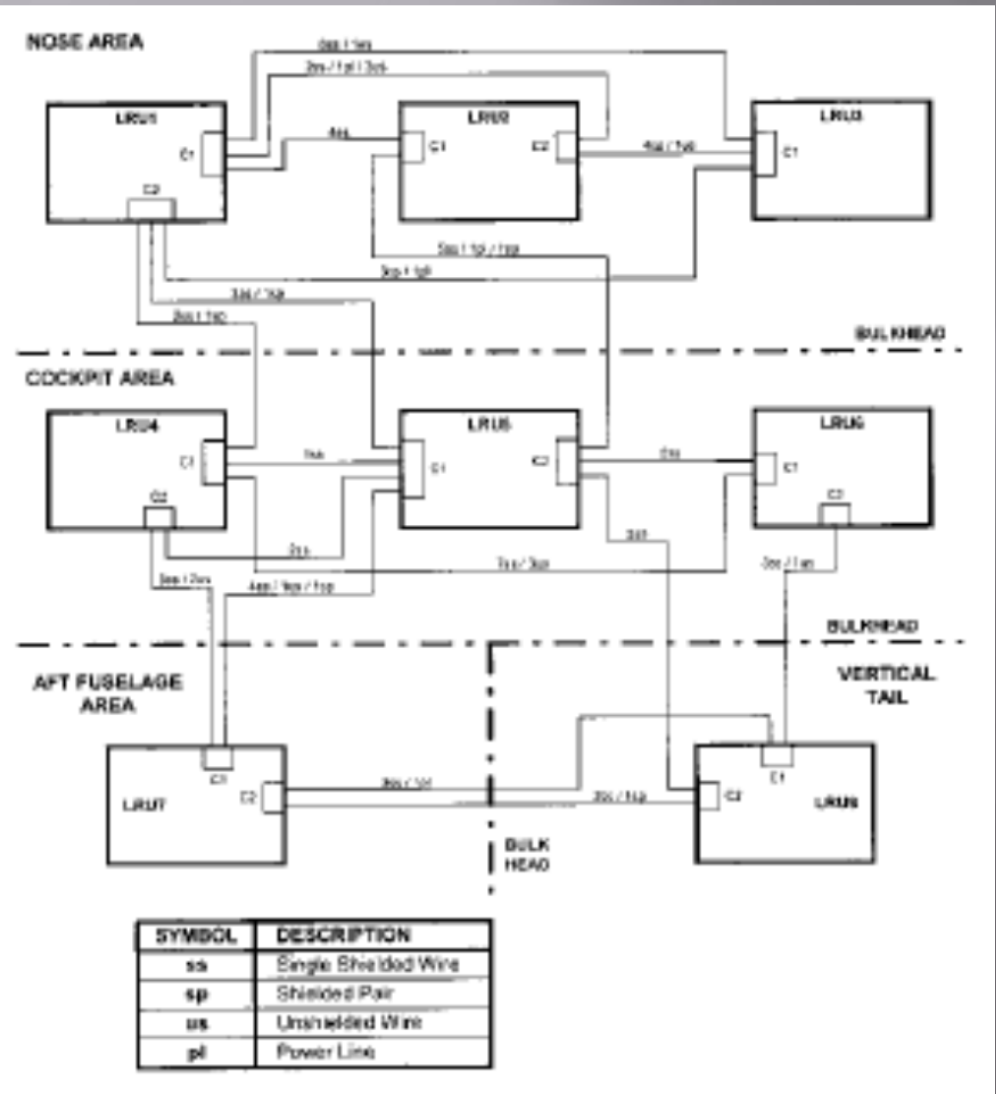

In the example given the following assumptions concerning the length of the wire bundles are made:

Wire bundles running within the Nose Area: $\leq 5 \mathrm{ft}$

Wire bundles running within the Cockpt: Area: $s 5 \mathrm{ft}$

Wire bundles running from Nose Area to Cockplt Area: $5 \mathrm{t} \leq \mathrm{X} \leq 15 \mathrm{n}$

Wire bundles running from Fuselage Tall Area to Nose Area: $235 \mathrm{ft}$

Wire bundles running from the Fuselage Area to Cockplt Area: $15 \mathrm{ft} \leq \mathrm{X} \leq 35 \mathrm{ft}$

Wire bundles running within the Fuselage Tall Area: $5 \mathrm{f} \leq \mathrm{X} \leq 15 \mathrm{f}$

Wire bundles running from Vertical Tall to Fuselage Tall Area: $15 \mathrm{ft} \leq \mathrm{X} \leq 35 \mathrm{ft}$

Wire bundles running from Vertical Tall to Cockpt: Area: $235^{\text {nt }}$

Based upon these assumptions, the requirement for each connector can be establlshed:

Since these wire bundes contain shlelded wires then Waveform 1 and Waveform 3 are applicable (NOTE: In other installations other wavefoms may apply).

It should be noted that the margin selected (Le., $6 \mathrm{~dB}$ ) for the various examples 15 simply a level selected and in no way should be taken as a requirement. Other margins have been accepted by the authorttes to show compllance.

Wavetorm 1 requirements:

LRU1 connector C1:

Total Low impedance Conductors routed within the Nose Area:

$-655+285+455+1 \mathrm{pl}$

- 13 wires \& 320 A (from Table 7)

$-4160 \mathrm{~A}$

With attenuation due to adjacent low Impedance conductors for wire bundle $\leq 15$ ft: $-16 \mathrm{~dB}$ (from Table 6)

$0.158^{*} 4160-660 \mathrm{~A}$

Add 6 dB for margin: Total Test Current required: $1320 \mathrm{~A}$ 


\section{Protection Design}

- Identify Critical Hardware

- Next, it is necessary to identify any critical hardware that could be impacted by the newly defined external and internal lightning environments generated by the zoning and tailoring processes previously discussed. The hardware so identified is not necessarily all electrical or electronic. It may include external OML mounted components, or even part of the OML itself. Or, it may include hydraulic or fuel system components that could be in a defined current path, and thus subject to possible arcing or local heating effects. It may include hardware that is absolutely essential for safe flight operations, or it may include hardware that is not absolutely essential for safe flight operations, but that is essential for mission completion.

- Whatever hardware is identified in this step must have the appropriate requirements for exposure levels, as determined in the previous steps, levied against it for design and certification purposes.

- Establish Protection Criteria

- The final step is to establish how the hardware identified can be protected from levels that are too severe for the hardware alone. This can range from the addition of shielding to the incorporation of various transient protection devices, alternate circuit designs, or additional electrical bond paths that are able to shunt excessive currents or voltages away from the sensitive hardware. 


\section{Summary}

- In summary, lightning is an insidious and random aspect of the natural environment with which all spacecraft programs have to deal with in some fashion. It is a threat to launch \& flight operations, and ground processing facilities \& processes. No matter how it is dealt with, lightning brings with it significant cost and impact, whether we are talking about facility and personnel protection, vehicle design, or launch delays and retesting of hardware exposed to large magnitude events.

- Lightning activity prediction and detection is very important, but is only a part of an overall successful protection approach.

- A successful approach integrates weather prediction and detection with solid, well designed protection schemes for facilities and flight hardware to address both direct and indirect effects.

- I said at the beginning that what I hope you take away with you today is a sense of what kind of threat and design impact lightning presents to us as spacecraft developers and engineers. I hope that in some way I have been successful. 


\section{Questions ?}

